\title{
Eigen analysis of wind-hydro joint frequency regulation in an isolated power system
}

\author{
Guillermo Martínez-Lucas*, José Ignacio Sarasúa, José Ángel Sánchez-Fernández \\ Department of Hydraulic, Energy and Environmental Engineering, Universidad Politécnica de Madrid, C/Profesor Aranguren 3, 28040 Madrid, Spain
}

\begin{abstract}
A B S T R A C T
The wind energy penetration rate is being increased in majority of European countries. However, a high pe-netration rate could endanger the stability of power systems, particularly in small islands. Hydropower plays an important role in the regulation and control of isolated power systems with renewable sources, but it may not be able to maintain the frequency within grid requirements. This is the case of El Hierro power system (Canary archipelago), where a hybrid wind-pumped storage hydropower plant (PSHP) was committed to reduce the use of fossil fuels. Currently, frequency regulation is only provided by the PSHP and diesel generators. Therefore, it is proposed that variable-speed wind turbines (VSWTs) contribute to frequency regulation, thereby minimizing the need for fossil fuels. This study aims to conduct an analysis on the effect of the VSWT contribution to frequency regulation in the power system of El Hierro. It is based on classical control tools from a linearized mathematical model considering different VSWT regulation strategies. The eigenvalues, damping ratio, and participation factors of the state variables have been obtained. The more significant oscillation modes in the dynamic response of the system have been identified. According to this modal analysis, a methodology for the adjustment of the PSHP and VSWT controller gains is proposed. An improvement in the quality of frequency regulation while maintaining the El Hierro system frequency within grid requirements has been proved based on simulating different events related to wind speed or variations in the power demand, using a nonlinear model of the combined wind-hydro power plant.
\end{abstract}

Keywords:

Hybrid wind-hydro power plant

Turbine governor

Variable-speed wind turbine

Synthetic inertia

Modal analysis

Eigenvalues

\section{Introduction}

Wind-based generation systems have become sustainable and environmentally friendly options to supply power in isolated or off grid locations [1]. In islands with isolated power systems, the development of renewable energies is not only linked to the environmental problems of fossil fuels. The costs of transporting these fuels to the places of consumption are higher than in continental systems. Therefore, their replacement by renewable resources can have a very positive economic impact [2]. Some examples of high renewable potential islands are the Aegean Islands [3], the archipelago of the Azores [4], and Canary Islands [5] in Europe, and The Yong Shu Island in South China Sea [6].

The power system frequency regulation impact of renewable energy sources depends mainly on its penetration rate and the system inertia [7]. Therefore, the negative effects associated with renewable energy sources, which are amplified in isolated systems may cause inadmissible frequency deviations. Nevertheless, in islands with wind potential, the increasing use of renewable energies has become the focus of interest of numerous researchers during the past few years $[8,9]$.
The vast majority of studies agree that the introduction of storage systems is the most effective way of significantly increasing wind penetration levels in power systems $[10,11]$. Focusing on the case of isolated systems, [12-14] have shown that the long-term variability in renewable energy can be managed well by combining wind and solar farms with pumped storage hydropower plants (PSHPs), which are able to compensate uncertainty in intermittent renewable resources. However, $[11,15,16]$ proved that PSHPs need complementary technologies in the short term (owing to its slowness caused by the water inertia), which are capable of injecting or absorbing power over brief periods that span a few seconds to avoid inadmissible frequency variations.

These rapid contributions to frequency regulations can be provided by variable-speed wind turbines (VSWTs) [17]. Different approaches can be found in the technical literature on the contributions of VSWTs to support frequency regulation $[18,19]$. In general, VSWTs-Type III and IV- provide negligible inertia because the rapid control of power electronic converters maintains a practically constant output power irrespective of changes in the frequency of the grid [20]. However, it is possible to achieve short-term inertial responses from VSWTs by 


\author{
Nomenclature \\ $\mathrm{A}_{\mathrm{r}} \quad$ Area swept by rotor blades $\left[\mathrm{m}^{2}\right]$ \\ $\mathrm{C}_{\mathrm{p}} \quad$ Variable-speed wind turbine (VSWT) power coefficient \\ h Net head [p.u.] \\ $h_{i} \quad$ Head at the end of the ith $\Pi$ element of the penstock [p.u.] \\ $\mathrm{H} \quad$ Wind turbine inertia constant [p.u.] \\ $\mathrm{k} \quad$ Load self-regulation coefficient [p.u.] \\ $\mathrm{K}_{\mathrm{dn}} \quad$ Constant that weights the frequency variation in the VSWT \\ $\mathrm{K}_{\mathrm{ic}} \quad$ Integral gain in proportional-integral (PI) blade pitch \\ angle compensation \\ $\mathrm{K}_{\mathrm{ip}} \quad$ Integral gain in PI blade pitch angle control \\ $\mathrm{K}_{\mathrm{i} \omega} \quad$ Integral gain in PI VSWT speed control \\ $\mathrm{K}_{\mathrm{pc}} \quad$ Proportional gain in PI blade pitch angle compensation \\ $\mathrm{K}_{\mathrm{pn}} \quad$ Constant that weights the frequency deviation in the \\ VSWT \\ $\mathrm{K}_{\mathrm{pp}} \quad$ Proportional gain in PI blade pitch angle control \\ $\mathrm{K}_{\mathrm{p} \omega} \quad$ Proportional gain in PI VSWT speed control \\ MFD Mean frequency deviation \\ n Frequency [p.u.] \\ $\mathrm{n}^{0} \quad$ Initial frequency [p.u.] \\ $\mathrm{n}_{\mathrm{ref}} \quad$ Reference frequency [p.u.] \\ $\mathrm{n}_{\mathrm{t}} \quad$ Number of segments in which the penstock is divided \\ $\mathrm{P}_{\mathrm{b}} \quad$ Base power [MW] \\ pdem Power demand [p.u.] \\ $\mathrm{p}_{\mathrm{h}} \quad$ Power supplied by PSHP [p.u.] \\ $\mathrm{p}_{\mathrm{n}}$ \\ Power reference provided by VSWT proportional and in- \\ ertial control [p.u.]
}

pnc Power supplied by VSWT converter [p.u.]

$\mathrm{p}_{\mathrm{nc}}{ }^{\mathrm{O}} \quad$ Initial power supplied by VSWT converter [p.u.]

$\mathrm{P}_{\text {wind }} \quad$ Wind mechanical power [MW]

$\mathrm{p}_{\text {wind }} \quad$ Wind mechanical power [p.u.]

$\mathrm{p}_{\omega} \quad$ Power reference provided by VSWT speed control [p.u.]

$\mathrm{q} \quad$ Flow through the turbine [p.u.]

$\mathrm{q}_{\mathrm{p}} \quad$ Flow at the penstock [p.u.]

$\mathrm{q}_{\mathrm{p}, \mathrm{i}} \quad$ Flow at the end of the ith $\Pi$ element of the penstock [p.u.]

$\mathrm{r} / 2 \quad$ Continuous head loss coefficient in the penstock [p.u.]

$\mathrm{s}_{\mathrm{w}} \quad$ Wind speed $[\mathrm{m} / \mathrm{s}]$

$\mathrm{T}_{\mathrm{e}} \quad$ Water elastic time $\left(\mathrm{L} / \mathrm{a}_{\mathrm{w}}\right)[\mathrm{s}]$

$\mathrm{T}_{\mathrm{m}} \quad$ Mechanical starting time [s]

$\mathrm{T}_{\mathrm{r}} \quad$ Hydro governor dashpot time constant [s]

$\mathrm{T}_{\mathrm{s}} \quad$ Time constant in servo motor transfer function [s]

$\mathrm{T}_{\mathrm{w}} \quad$ Penstock water starting time [s]

$\mathrm{z} \quad$ Nozzle opening [p.u.]

$\alpha_{i j} \quad C_{p}$ curve coefficients

$\delta \quad$ Hydro governor temporary speed droop

$\zeta \quad$ Damping ratio

$\beta \quad \quad$ VSWT blade pitch angle $\left[^{\circ}\right]$

$\beta^{0} \quad$ VSWT initial blade pitch angle [ $\left.{ }^{\circ}\right]$

$\beta_{\max } \quad$ VSWT maximum blade pitch angle $\left[{ }^{\circ}\right]$

$\lambda \quad$ Ratio of the rotor blade tip speed and wind speed

$\lambda_{\mathrm{i}} \quad$ Eigenvalue associated with each state variable

$\rho \quad$ Air density: $1.225 \mathrm{~kg} / \mathrm{m}^{3}\left[\mathrm{~kg} / \mathrm{m}^{3}\right]$

$\omega \quad$ VSWT rotational rotor speed [p.u.]

$\omega_{\text {ref }} \quad$ Reference VSWT rotational rotor speed [p.u.] modifying their control loops [21-24]. According to this idea, Renuka and Reji modelled a synthetic inertia of VSWTs in [25], underlining the important improvement in the minimum frequency peak (nadir). Prof. Gonzalez-Longat proposed different activation schemes for the synthetic inertia on VSWTs based on full converters in [26] and established practical limits for the gain of synthetic inertia control loop used in fullconverter VSWT generators in [27].

Primary and secondary frequency regulation can also be provided by VSWTs. Certainly, a nonoptimal operation point is reached in the VSWT power curve $[28,29]$, thus causing a loss in the wind resource harvesting and, as a consequence, incomings reduction. To mitigate this weakness, Mauricio et al. [30] presented a new method for improving the use of variable-speed wind energy conversion systems by modifying the inertial control scheme through the addition of a proportional loop that weights the frequency deviation. The inertial control loop and inertial and proportional control loop proposed allow the release of the stored fraction of kinetic energy in rotational masses to provide earlier frequency support, thus taking advantage of the rapid response capability of electronic power converters. Both control strategies do not need to have a regulation reserve, allowing a better use of wind resources. According to these strategies, the authors in [31] analysed the combined contribution to frequency regulation of a wind-hydro hybrid power plant equipped with a PSHP and VSWT in the El Hierro isolated system with $100 \%$ renewable generation, proposing a methodology based on exhaustive searches to adjust the controllers for each of the control strategies, obtaining successful results. The evaluation of the results obtained only by simulations should be completed with an analytical study of the dynamic model to analyse the intervention of the new control strategies in the system response. This analytical study is the main contribution of the present paper.

El Hierro is an island in the Canary archipelago which aims to become $100 \%$ free from carbon dioxide emissions [8]. To achieve this objective, a power hybrid wind-PSHP (W-PSHP) was committed in June 2014 to minimize the utilization of fossil fuels [32]. However, currently, VSWTs are not aimed at providing frequency regulation, underutilizing the island wind potential.

Different modern studies analyse the dynamics of small disturbances using classic control techniques, such as root locus plot, having been successfully applied to obtain recommendations for proportional-integral (PI) derivative speed governor tuning [33,34]. A procedure based on mathematical models of the controlled system is given in [35] for designing speed and active power controllers for hydro turbine units obtaining the controller parameters from closed-loop poles. An improvement in the system frequency owing to VSWTs equipped with adequately controlled doubly fed induction machines is shown in [36] through an eigenvalue analysis. In [37], the authors analysed different aspects of small disturbance voltage stability from eigenvalues position, studying the influence between the dynamic characteristics of the system such as those of generators, controllers, and loads. Different practical tuning criteria for the governor of hydropower plants equipped with long conduits are proposed in [38-40] by using the pole placement method. In [41], the authors presented a case study illustrating the effects of pressure pulsations due to vortex rope precession on the draft tube of Francis turbines through a modal analysis combined with frequency-domain and time-domain simulations.

The aim of this study is to analyse the effect of the VSWT contribution to frequency regulation in the isolated power system of El Hierro Island with classical control tools. The study of a linearized model is carried out for this hybrid wind-hydro power plant for each of the strategies described above (inertial, proportional, and their combination) by obtaining the eigenvalues, damping ratios, and participation factors of the state variables, identifying from the modal analysis the oscillation modes that interfere with the dynamic behaviour of the system. The influence of the PSHP and VSWT controller gains in varying the participation of the state variables in the oscillation modes is analysed. According to the study of the damping ratio and the oscillation modes, a methodology for the adjustment of the PSHP and VSWT controller gains based on the eigen analysis is proposed. The modal analysis and the proposed adjustment of the PSHP and VSWT controller gains for each control strategy have been verified by realistic 
simulations carried out using the completely nonlinear model.

This paper is organized as follows. In Section 2, the hybrid W-PSHP and El Hierro power system are described. The W-PSHP nonlinear dynamic model is presented in Section 3. Section 4 describes the simplifications assumed for the modal analysis and the model linearization. The developed modal analysis, proposing a controller gains adjustment method, is presented in Section 5. In Section 6, some realistic events simulated to support the modal analysis and the controller gains adjustment method are presented. Finally, the main conclusions of this study are outlined.

\section{Hybrid wind-hydro power plant and power system description}

El Hierro is an island belonging to the Canary Islands archipelago, which was declared as a biosphere reserve by UNESCO. The island aims to become $100 \%$ free of greenhouse gas emissions [8]. The electrical capacity of the island is $37.8 \mathrm{MW}$, mainly distributed by diesel generators and a W-PSHP of $22.8 \mathrm{MW}$. The PSHP has $11.32 \mathrm{MW}$ capacity and the five VSWTs ENERCON-E70 [42] provide the remaining power [43]. The maximum peak demand in 2016 was $7.7 \mathrm{MW}$, whereas the minimum was approximately $4 \mathrm{MW}$ [44]. The VSWTs are not assigned to frequency regulation; therefore, as PSHP inertia and regulation capacity are insufficient to absorb power demand and wind power fluctuations, the contribution of diesel generators is required for frequency regulation. It is expected that the percentage of demand supplied by renewable resources will be increased. In this context, it is assumed that the W-PSHP operates in isolation. The Gorona del Viento W-PSHP data used in the model and the layout shown in Fig. 1 have been extracted from $[42,45,46]$.

\section{Hybrid wind-hydro power plant model description}

A PSHP and VSWT connected to an isolated system have been modelled in MATLAB Simulink. In addition to the PSHP frequency regulation, the possible contribution of the VSWT to frequency regulation will be analysed. Therefore, the simulation model will include the dynamic behaviour of the PSHP and VSWT. The PSHP will operate in generating mode during all simulations. Because the PSHP electromagnetic transients and VSWT converter dynamics are supposed to be very rapid compared with the other components of the model, both will be neglected. Therefore, the VSWT inertia is thus uncoupled from the electric system. Fig. 2 shows the block diagram of the hybrid wind-hydro power plant and the power system.

\subsection{Power system model description}

As stated above, the PSHP is connected to an isolated system comprising intermittent energy sources and loads. Thus, the frequency dynamics described by Eq. (1) are the result of the imbalance between the sum of the hydroelectric $\mathrm{p}_{\mathrm{h}}$ and wind converter generated power $\mathrm{p}_{\mathrm{nc}}$ and the power demanded by the loads $\mathrm{p}_{\mathrm{dem}}[47]$.

$T_{m} \frac{d n}{d t}=\frac{1}{n}\left(p_{h}+p_{n c}-p_{d e m}\right)-k \Delta n$

Inertial mechanical time refers only to PSHP. VSWTs are supposed to be connected to the system through a frequency converter, and do not contribute to the system inertia. The parameter $\mathrm{k}$ includes the load frequency sensitivity and it is assumed that $\mathrm{k}=1$, which corresponds to a static load.

\subsection{PSHP model description}

\subsubsection{Penstock}

The transient flow in conduits is described by expressions of conservation of mass and momentum [48]. Because of the penstock length, the water and pipe material elasticity cannot be neglected [39] and different approaches can be found in specialised literature. In recent years, some authors $[45,49]$ had obtained good results with their hydro power plant models using a lumped parameter approach.

This approach, which has been used in this study, leads to a system of ordinary differential equations that can be represented as a series of consecutive $\Gamma$-shaped elements, where the conduit properties (inertia, elasticity, and friction) are proportionally assigned to the segment length. The 'orientation' and 'configuration' of the $\Gamma$-shaped elements may vary according to the upstream and downstream boundary conditions of the pipe. Eqs. (2) and (3) of the penstock dynamics are:

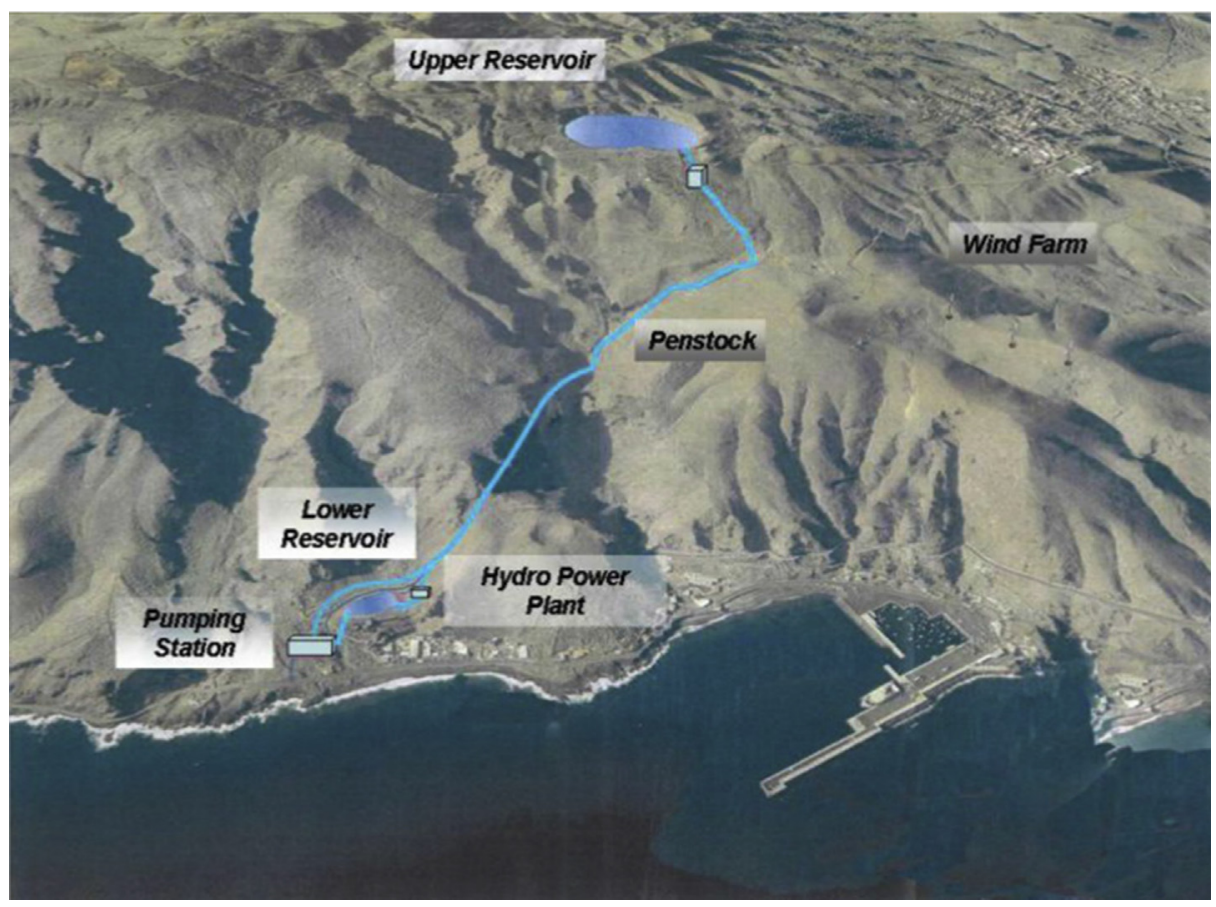

Fig. 1. El Hierro combined wind and PSHP layout. 


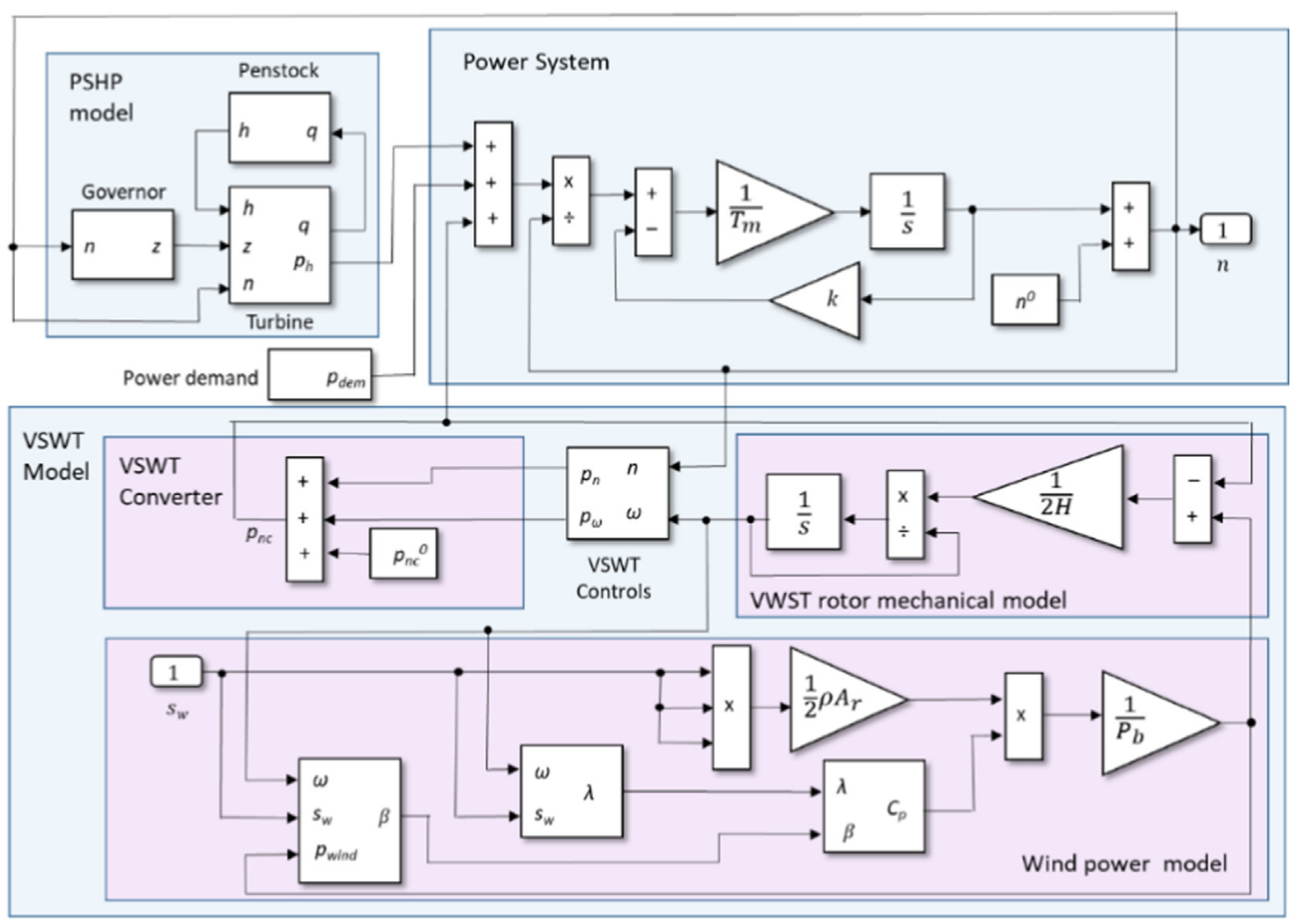

Fig. 2. Block diagram of hybrid wind-hydro power plant and power system.

$\frac{d h_{i}}{d t}=n_{t} \frac{T_{w}}{T_{e}^{2}}\left(q_{p, i}-q_{p, i+1}\right)$

$\frac{d q_{p, i}}{d t}=\frac{n_{t}}{T_{w}}\left(h_{i}-h_{i+1}-\frac{r}{2 n_{t}} q_{p, i}\left|q_{p, i}\right|\right)$

The number of segments $n_{t}$ determines the order of the system. For this PSHP, authors in [39] demonstrated that simulations assuming a lumped parameter approach with 10 segments match significantly with simulations provided by the transfer function proposed in [50].

\subsubsection{Turbine}

Turbine is modelled considering the relation between the flow, head, and nozzle opening [50]. The assumed generated torque corresponds to ideal conditions in Pelton turbines, where the absolute fluid speed is twice the runner peripheral speed for rated conditions [39].
The modelled hydropower plant has more than one identical unit; each unit is supposed to operate in an identical manner at the same time. Therefore, a single equivalent turbine has been considered in the remaining parts of this study.

\subsubsection{PSHP governor}

The proposed PSHP governor model, which is based on [47], is formulated in Eq. (4). The main function of this governor is to control the unit speed by monitoring the frequency error signal, modifying the turbine nozzles, and regulating the water flow through the penstock. The error signal is processed by a conventional PI controller. The limits in the positions of the turbine nozzles and their rates of change are considered in the model using a rate limiter and a saturation element.

$\Delta z=\left[\frac{1}{\delta}+\frac{1}{\delta T_{r}} \int d t\right]\left(n_{r e f}-n\right)$

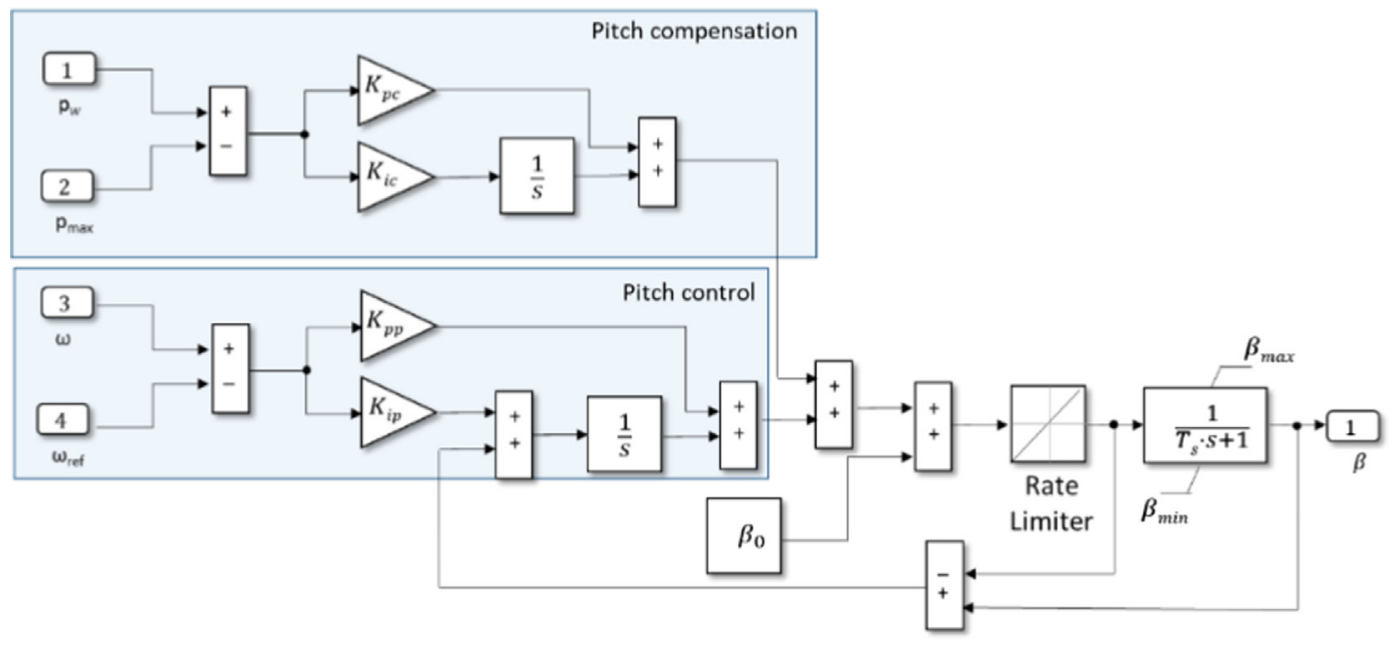

Fig. 3. Block diagram of pitch control model. 


\subsection{VSWT model description}

\subsubsection{Wind power model}

The power extracted from the wind is modelled using the mathematical function in Eq. (5) [51,52].

$P_{\text {wind }}=\frac{\rho}{2} A_{r} s_{w}^{3} C_{p}(\lambda, \beta)$

The power coefficient $C_{\mathrm{p}}$ is a fourth order function of the turbine tip speed ratio $\lambda$ and the pitch angle $\beta$ [52].

\subsubsection{Blade pitch angle control}

Fig. 3 shows the block diagram of the blade pitch angle control. This control is a combination of a conventional pitch angle control and pitch compensation. The conventional pitch angle control implements a PI control that computes the difference between rotor and reference rotor speeds [53]. Furthermore, the pitch angle control considers the compensation through a different PI control that computes the difference between the mechanical wind power and maximum rated power for each wind speed [54].

It is expected that blade movements were smoothed if pitch control is improved considering advanced techniques [55-57]. However, the simplest controller was considered to make conclusions more general. Blade pitch angle variations are slow enough to be decoupled from the dynamic responses of other variables. In the literature, there is agreement on the value of these gains. Therefore, gains proposed in [51,52] have been assumed. Blade pitch angle control parameters are listed in Table 1.

The reference speed $\omega_{\text {ref }}$ is usually 1.2 p.u. but it can be lower. Speed reference is incorporated in the model by using a quadratic expression [51], which has been calibrated by considering the operational curves provided by the manufacturer [42].

\subsubsection{Mechanical model of rotor}

The reduced order two-mass shaft model is the most appropriate for transient stability analysis [58], however some manufacturers recommend the use of the simple one-mass shaft model in cases where the power converter decouples the generator from the grid [59]. The VSWT model includes the rotor inertial equation for the wind turbine rotor (Eq. (6)) [51].

$\frac{d \omega}{d t}=\frac{1}{2 H} \frac{1}{\omega}\left(p_{w}-p_{n c}\right)$

\subsubsection{VSWT inertial and proportional control loops}

The regulating capacity of the VSWT will be used. In this study, the VSWT control strategies proposed in [31] (inertial, proportional, and their combination) are analysed. Owing to the existence of the wind energy conversion system, the inertial and proportional control loops add a power signal $\Delta p_{n}$ to the power reference output to be tracked by the converter (Eq. (7)) [30]:

$\Delta p_{n}=\left[K_{p n}+K_{d n} \frac{d}{d t}\right]\left(n_{r e f}-n\right)$

$K_{\mathrm{dn}}$ weights the RoCoF, while $\mathrm{K}_{\mathrm{pn}}$ is a weighting constant of the frequency deviation. When inertial or proportional control is executed individually, the other controller is disabled by cancelling the corresponding gains from Eq. (7). A methodology to adjust gain values will be described in the following section.

\subsubsection{VSWT rotor speed control}

Because of VSWT contribution to frequency regulation through the inertial and proportional control loops, a wind turbine rotor speed control is required. This last control loop restores the VSWT rotor optimal speed after a frequency disturbance; otherwise, the VSWT will be destabilized.
This speed control, which controls the rotational speed by regulating the electromagnetic torque, aims to recover the optimal speed once the frequency transient has subsided [60]. Actually, when the wind speed is very low, the rotor speed is only controlled by changing the generator torque while the blade pitch is constant. Authors are aware of the existence of advanced maximum power point tracking controllers based on modern control techniques [61]. However, it was considered the simplest controller to make the conclusions more general. Therefore, a PI controller obtains a power reference, $\Delta \mathrm{p}_{\omega}$ (Eq. (8)), based on the difference between the rotational speed and the optimal rotational speed [30].

$\Delta p_{\omega}=\left[K_{p \omega}+K_{i \omega} \int d t\right]\left(\omega-\omega_{r e f}\right)$

The total power supplied by the electronic converter (Eq. (9)) will be the sum of the mechanical power initially produced by the wind and both power increments that have been previously described. As the converter internal dynamics is much faster than the processes studied in this paper, the converter action is supposed to be instantaneous; the power electronic controller is assumed to work ideally.

$p_{n c}=p_{n c}^{0}+\Delta p_{n}+\Delta p_{\omega}$

\section{Linearized reduced order model}

For control design purposes, a linearized model for small perturbation analysis in the neighbourhood of an initial equilibrium operating point is usually employed. However, considering that a linearized model is not enough to perform a systematic analysis, the previously described model will be simplified because some of the phenomena included are negligible when small disturbances occur. The assumed simplifications are described in the following sections.

\subsection{Reduced order model}

\subsubsection{One-segment lumped parameter approach}

In [39], the authors verified that the simplest one П-shaped segment model having one series branch and two shunt branches would be sufficiently accurate to consider penstock elasticity effects. Therefore, for analytic purposes, the penstock is modelled following this recommendation obtaining a second-order model, whose state variables are $\left\{\Delta q_{p}, \Delta h\right\}$.

\subsubsection{VSWT model simplification}

Assuming small perturbations in the neighbourhood of an initial equilibrium operating point and a short-term framework, the mechanical power from the wind can be considered constant $[30,62]$. Furthermore, because of the slowness of blade pitch movements, these ones have been neglected and the pitch angle position has been considered static for analytic purposes.

\subsection{Linearization}

Some of the expressions that model the system described previously are composed of nonlinear terms and are not suitable for the modal analysis of the system. They are also not suitable for controller gains tuning using linear methods. Therefore, a linearized model is proposed for small perturbation analysis in the neighbourhood of an initial equilibrium operating point.

Table 1

VSWT pitch control parameters.

\begin{tabular}{cccccccc}
\hline $\mathrm{K}_{\mathrm{pc}}$ & 3 & $\mathrm{~K}_{\mathrm{pp}}$ & 150 & $\beta_{\max }$ & 27 & $\mathrm{~K}_{\mathrm{pw}}$ & 0.10 \\
\hline $\mathrm{K}_{\mathrm{ic}}$ & 30 & $\mathrm{~K}_{\mathrm{ip}}$ & 25 & $\mathrm{~T}_{\mathrm{s}}$ & 0.1 & $\mathrm{~K}_{\mathrm{i} \omega}$ & 0.010 \\
\hline
\end{tabular}


The linearized model of a hydraulic turbine can be written assuming linear variations of flow and torque respect to net head, rotational speed and wicket gate position. Friction losses in the penstock have also been linearized.

\section{Eigen analysis and controller tuning methodology}

Based on the VSWT control loops described previously, three control strategies are proposed in [31]. Inertial control strategy, which takes the RoCoF as the control loop input (case ' $A$ '), proportional control strategy, which takes the variation in frequency as the control loop input (case ' $\mathrm{B}$ '), and finally, inertial and proportional control strategy, which takes both variations as the control loop input (case ' $C$ '). These inertial and proportional control loops allow a fraction of the kinetic energy stored in rotational masses to be released to provide earlier frequency support, thereby taking advantage of the rapid response capability associated with electronically controlled converters. These control strategies can allow no regulation reserve, and thus, a better use of the wind resource is achieved. A base case in which the VSWTs are not assigned to contribute to frequency regulation is considered to highlight system improvements owing to the VSWT contribution to frequency regulation. In the cases in which the VSWTs do not provide frequency regulation or it is provided through the inertial control loop, the dynamic system is a fourth-order system because the state variables $\left(\boldsymbol{\Delta} \omega, \boldsymbol{\Delta} \boldsymbol{p}_{\omega}\right)$ are not active in the system. When the VSWTs provide proportional frequency regulation (or inertial and proportional), the dynamic system is a sixth-order system.

The main problem caused by long conduits, studied in $[39,40]$, is the transmission of water elasticity oscillations to the generated power, and thus to the system frequency in isolated systems. Therefore, the oscillating modes that interfere with the dynamic behaviour of the system are identified from the modal analysis, differentiating the dominant variables of each oscillation mode. The influence of the PSHP and VSWT controller gains in varying the participation of the state variables in the oscillation modes is analysed. This can reduce the influence of water inertia and elasticity on the system frequency, preventing the hydraulic oscillatory phenomena that are transmitted to the electrical network. The study of small disturbance dynamics of the linearized model is carried out for this hybrid wind-hydro power plant for each of the strategies described above. The eigenvalues, damping ratio, and participation factors of the state variables in the oscillation modes are obtained. From the study of the damping ratio and oscillation modes, a method for tuning the PSHP and VSWT controller gains based on the eigen analysis is proposed.

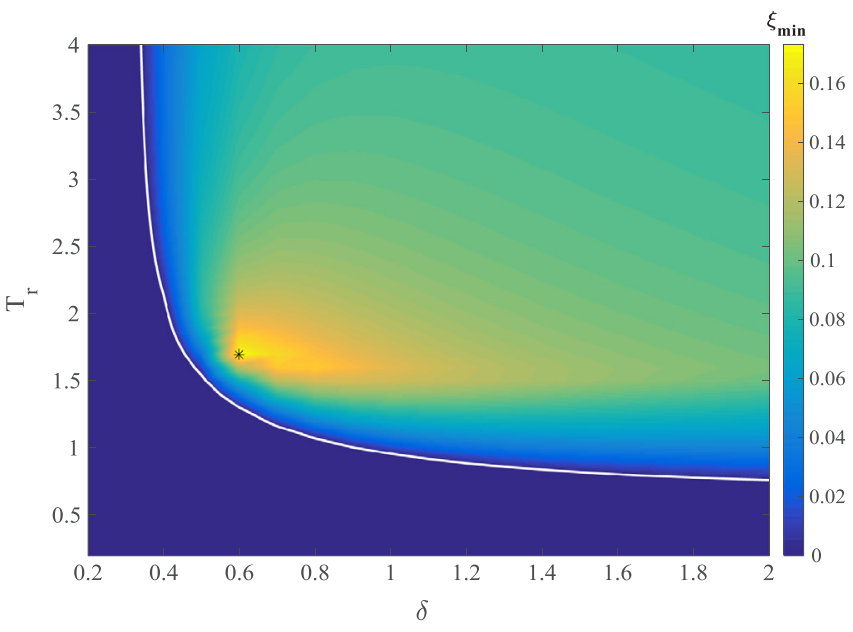

(a)
The modal analysis starts from the calculation of the state matrix eigenvalues. The eigenvalues $\left(\lambda_{i}\right)$ are the main indicators of the dynamics and stability of the system. One of the classic tools that allow analysing the dynamics of the system from the position of the poles is the root locus, which will be used in the modal analysis. The participation factors are employed to measure the relative association between the ith state variable and the jth eigenvalue [63]. Three oscillation modes can be found in this system:

- Oscillation mode I: Water elasticity mode, in which the state variables of the hydraulic system $\left(\Delta h, \Delta q_{p}\right)$ have the highest participation. In root locus figures, this mode is plotted in blue colour.

- Oscillation mode II: Electromechanical mode, in which the state variables of the PSHP governor and the system frequency $(\Delta z, \Delta n)$ have the highest participation. In root locus figures, this mode is plotted in red colour.

- Oscillation mode III: Aeromechanical mode, in which the state variables of the VSWT $\left(\Delta \omega, \Delta p_{\omega}\right)$ have the highest participation. This oscillation mode appears when the VSWTs are aimed at contributing proportionally to frequency regulation (cases ' $\mathrm{B}$ ' and ' $\mathrm{C}$ '). In root locus figures, this mode is plotted in green colour.

Moreover, the damping ratio $\left(\xi_{i}\right)$ of the corresponding oscillation mode can be obtained from the state matrix. Analyses involve damping ratios corresponding to different eigenvalues in the system for each strategy. The smallest damping ratio is selected as the main indicator of the system stability [64]. Therefore, the tuning criterion is based on obtaining the VSWT and PSHP controller gains that provide the higher smallest damping ratio. Two wind speeds have been compared to analyse their influence on the behaviour of the system. The electric demand is the same in both cases, so PSHP operating point will be adjusted to cover this power demand taking into account the different power supplied by the VSWT.

\subsection{Base case: frequency regulation provided by PSHP}

A base case in which the frequency regulation is only provided by the PSHP is considered to highlight in the following sections the system improvement owing to the VSWT contribution to frequency regulation. Fig. 4 shows the system's smallest damping ratio as a function of PSHP controller gains $\left(\delta, T_{r}\right)$ when the VSWTs do not contribute to frequency regulation, for a constant speed of $10 \mathrm{~m} / \mathrm{s}$ and $20 \mathrm{~m} / \mathrm{s}$. The white line corresponds to the null damping ratio, dividing the unstable region coloured in dark blue. The PSHP controller gains that correspond to the

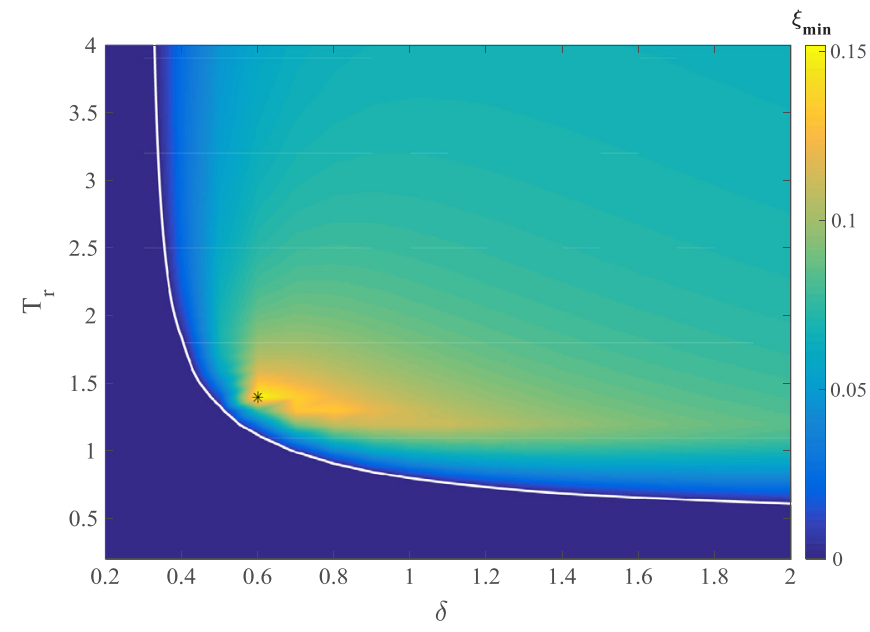

(b)

Fig. 4. Smallest damping ratio when VSWTs do not provide frequency regulation being $\mathrm{sw}=10 \mathrm{~m} / \mathrm{s}(\mathrm{a}) \mathrm{and} \mathrm{sw}=20 \mathrm{~m} / \mathrm{s}(\mathrm{b})$. 
maximum smallest damping ratio are marked with an asterisk for both speed regimes.

Table 2 lists the PSHP controller gains, eigenvalues, damping ratios, and participation factors applying the proposed criterion when frequency regulation is provided only by the PSHP for wind speeds of $10 \mathrm{~m} / \mathrm{s}$ and $20 \mathrm{~m} / \mathrm{s}$. Although the sum of the variables' participation factors does not reach the minimum value of 0.8 established in [63], two oscillation modes are identified corresponding respectively to elastic phenomena oscillations and PSHP governor oscillations, that is, the isolated system frequency. Both oscillation modes are very strongly interrelated, which may cause the elastic water mode oscillations to be transmitted to the electrical system.

To analyse the influence of the PSHP governor gains in the system dynamics, the root locus plot when parameter $\delta$ is varied assuming no VSWT contribution to frequency regulation is shown in Fig. 5. The instability region (positive real half plane) has been shaded grey. The poles corresponding to the tuning used are marked with an asterisk. As can be observed, the criterion based on obtaining the maximum smallest damping ratio tends towards the double complex pole criteria proposed in [39]. Owing to the proximity of the poles, the damping ratios of both oscillation modes are similar.

\subsection{Case 'A': inertial VSWT contribution to frequency regulation}

Owing to the frequency requirements $(50 \mathrm{~Hz} \pm 0.15 \mathrm{~Hz})$ established by the Spanish transmission system operator (TSO) for isolated systems [65], the electromechanical oscillation, in which the system frequency is one of the dominant state variables, is controlled. To verify if the inertial regulation of the VSWT decreases the participation of the hydraulic variables in the electromechanical mode, the evolution of participation factors of the dominant state variables into that mode due to VSWT inertial contribution to frequency regulation are shown in Fig. 6. The participation factor of the variables $(\Delta z, \Delta n)$ in the electromechanical mode, increases as the VSWT synthetic inertia increases, decreasing the participation of the water elasticity mode dominant variables. When the inertial contribution is null $\left(\mathrm{K}_{\mathrm{dn}}=0\right)$, the electromechanical oscillation mode is strongly influenced by the dominant variables of the water elasticity mode $\left(\Delta h, \Delta q_{p}\right)$ with the oscillation of this mode being transmitted to the power system. The water elasticity mode has a higher participation factor in cases when the wind speed is low than in cases when the wind speed is high. This is because the PSHP operating point is higher in the first than in the second case because the power supplied by the VSWT is lower. Please note that the power demand is assumed to be constant.

According to [31], adjusting the PSHP and VSWT regulators' joint gains is recommended. Fig. 7 shows the system's smallest damping ratio of case 'A', for a constant speed of $10 \mathrm{~m} / \mathrm{s}$ and $20 \mathrm{~m} / \mathrm{s}$, in relation to the three adjustable gains. The continuous lines correspond to $K_{d n}$ values that provide the higher smallest damping ratio for each pair of values $\left(\delta, T_{r}\right)$. The white line corresponds to the null damping ratio, dividing the unstable region coloured in dark blue. The new PSHP and VSWT controller gains, which correspond to the maximum smallest damping ratio, are marked with an asterisk for both speed regimes.

Fig. 8 shows the root locus, which is plotted by fixing the PSHP

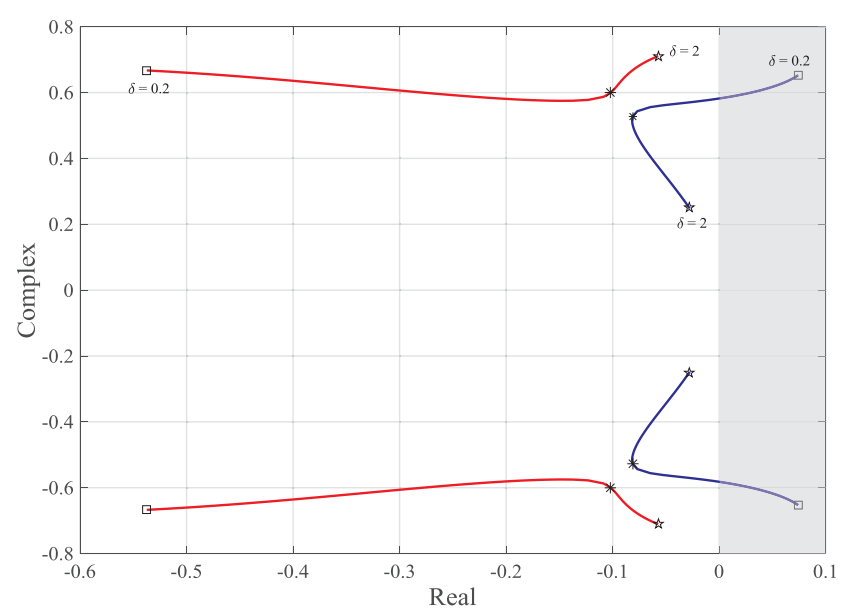

Fig. 5. Root locus plot when VSWTs do not contribute to frequency regulation ( $\mathrm{sw}=20 \mathrm{~m} / \mathrm{s}$ ). System poles corresponding to the proposed tuning are marked with an asterisk.
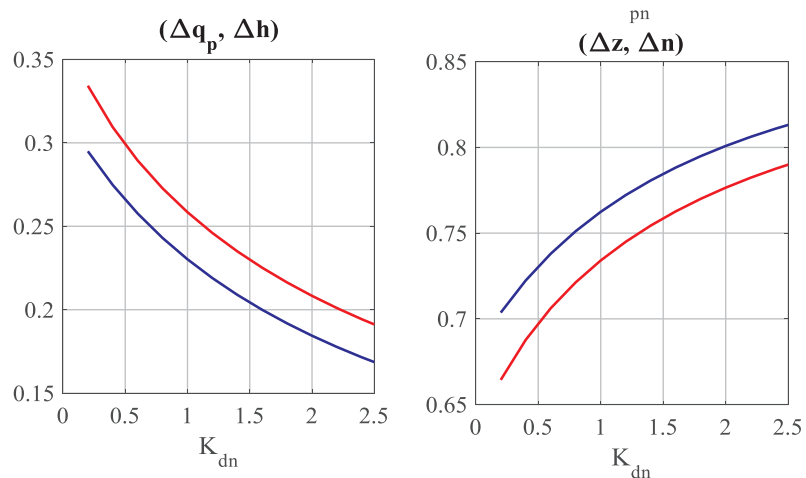

Fig. 6. Participation factors of dominant variables into electromechanical mode evolution due to VSWT inertial frequency regulation. Blue lines represent constant wind speed of $20 \mathrm{~m} / \mathrm{s}$ scenario while red lines represent $10 \mathrm{~m} / \mathrm{s}$ scenario. (For interpretation of the references to colour in this figure caption, the reader is referred to the web version of this article.)

controller gains and varying the gain of the inertial control loop. The instability region (positive real half plane) has been shaded grey. The controller gains obtaining the smallest damping ratio are marked with an asterisk. The poles corresponding to the base case are marked with diamonds. The displacement of the poles in the plane can be observed: the pole of the electromechanical mode moves towards the negative real half plane, whereas the pole of the water elasticity mode moves towards the opposite direction. However, owing to the increase in the real part of the pole associated with the electromechanical mode, the system behaviour is improved. It is noteworthy that with these PSHP controller gains, the system would be unstable if the VSWTs did not provide frequency regulation $\left(K_{d n}=0\right)$ because of having the pole corresponding to the water elasticity mode in the positive real half plane. Furthermore, it is confirmed that a practical limit in the inertial

Table 2

PSHP controller gains and participation factors when VSWTs do not provide frequency regulation.

\begin{tabular}{|c|c|c|c|c|c|c|c|c|c|c|c|}
\hline \multirow{2}{*}{$\begin{array}{l}\mathrm{s}_{\mathrm{w}} \\
(\mathrm{m} / \mathrm{s})\end{array}$} & \multicolumn{2}{|c|}{ PSHP gains } & \multirow[t]{2}{*}{$\lambda_{\mathrm{i}}$} & \multirow[t]{2}{*}{$\zeta_{\mathrm{i}}$} & \multicolumn{6}{|c|}{ Participation factors } & \multirow[t]{2}{*}{ Oscillation mode } \\
\hline & $\delta$ & $\mathrm{T}_{\mathrm{r}}$ & & & $\Delta q_{p}$ & $\Delta h$ & $\Delta z$ & $\Delta n$ & $\Delta \omega$ & $\Delta p_{\omega}$ & \\
\hline \multirow[t]{2}{*}{10} & 0.6 & 1.7 & $-0.113 \pm j 0.592$ & 0.187 & 0.244 & 0.357 & 0.225 & 0.174 & - & - & I \\
\hline & & & $-0.085 \pm j 0.481$ & 0.173 & 0.114 & 0.253 & 0.343 & 0.290 & - & - & II \\
\hline \multirow[t]{2}{*}{20} & 0.6 & 1.4 & $-0.102 \pm j 0.600$ & 0.168 & 0.233 & 0.334 & 0.236 & 0.197 & - & - & I \\
\hline & & & $-0.081 \pm \mathrm{j} 0.528$ & 0.152 & 0.142 & 0.264 & 0.318 & 0.276 & - & - & II \\
\hline
\end{tabular}




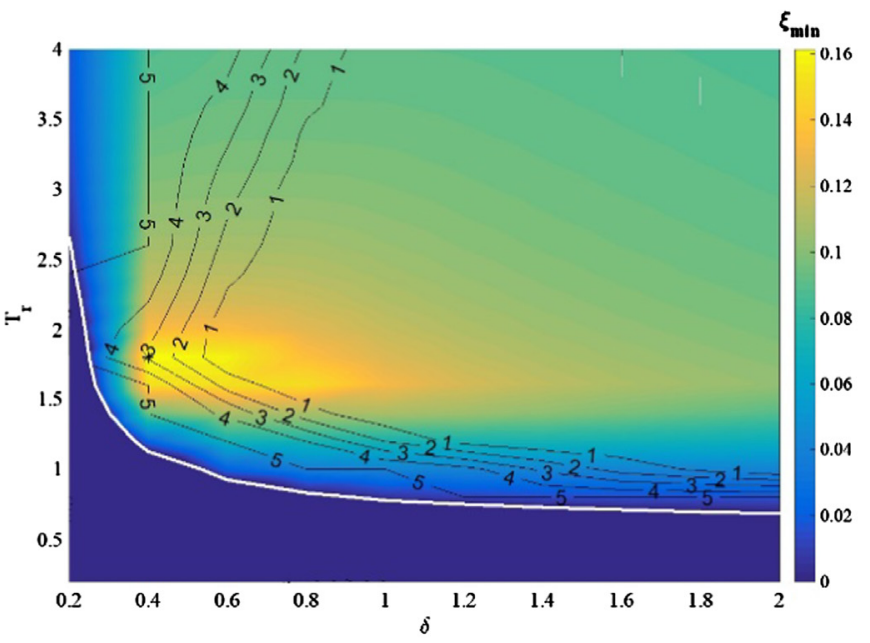

(a)

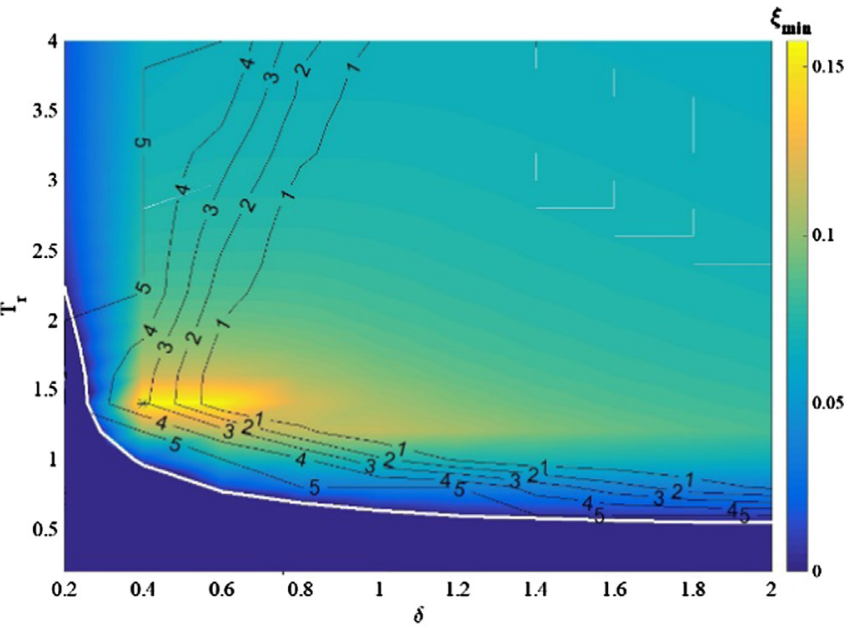

(b)

Fig. 7. Smallest damping ratio when VSWTs provide frequency regulation through an inertial control loop being $\mathrm{sw}=10 \mathrm{~m} / \mathrm{s}(\mathrm{a})$ and $\mathrm{sw}=20 \mathrm{~m} / \mathrm{s}(\mathrm{b})$.

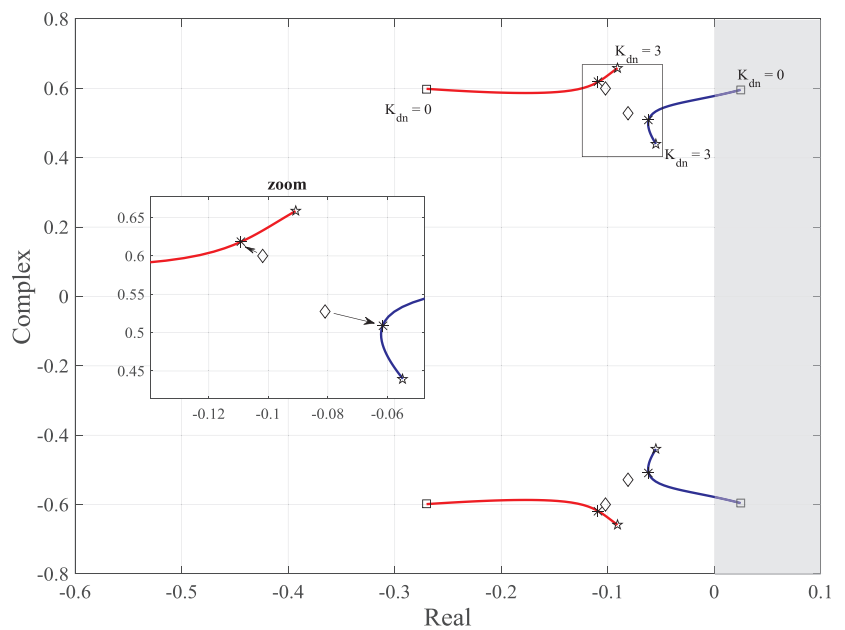

Fig. 8. Root locus plot when VSWTs contribute to frequency regulation with proportional control loop (sw $=20 \mathrm{~m} / \mathrm{s}$ ).

contribution of VSWT exists, as it is stated in [27] because the poles tend to the real half plane. This is the reason that the proposed values for the VSWT inertial control loop gains for interconnected systems are not suitable in isolated systems. The value proposed in [30] $\left(\mathrm{K}_{\mathrm{dn}}=15\right)$ applied in an isolated system, as the case studied, caused the real part of the eigenvalues to be positive, destabilizing the system as demonstrated in [31] with different simulations.

Table 3 lists the PSHP and VSWT controller gains, eigenvalues, damping ratios, and participation factors by applying the proposed criterion when the VSWTs provide inertial frequency regulation for wind speeds of $10 \mathrm{~m} / \mathrm{s}$ and $20 \mathrm{~m} / \mathrm{s}$. The participation factors have been modified, decreasing the presence of variables associated with the water elasticity in the electromechanical mode, thus preventing the hydraulic oscillations to be transmitted to the power system.

\subsection{Case 'B': proportional VSWT contribution to frequency regulation}

When the VSWTs provide frequency regulation through a proportional control loop, the aeromechanical oscillation mode appears (now the dynamic system is a sixth-order system). Fig. 9 shows the evolution of the participation of the dominant state variables into the electromechanical mode. As can be observed, the participation factor of the variables $(\Delta z, \Delta n)$ in the electromechanical mode, increases as the VSWT proportional contribution rises, reaching a maximum for $\mathrm{K}_{\mathrm{pn}}$ values between 1.5 and 2-independently of the wind speed-decreasing the participation of the water elasticity dominant variables. This is because the positive participation variation rate of the aeromechanical dominant variables into the electromechanical mode is higher than the negative variation rate of the participation of the water elasticity dominant values.

In this case, the water elasticity mode also has a higher participation factor in cases when the wind speed is low than in cases when the wind speed is high.

Following the recommendations and the methodology described previously, Fig. 10 shows the system's smallest damping ratio for case 'B'. The white line corresponds to the null damping ratio, dividing the unstable region coloured in dark blue. The new PSHP and VSWT controller gains, which correspond to the maximum smallest damping ratio, are marked with an asterisk for both wind speed regimes. The values of the PSHP governor gains are significantly different from those obtained in the base case.

Fig. 11 shows the root locus when the VSWTs provide frequency regulation through a proportional control loop having obtained the PSHP and VSWT controller gains jointly. The instability region (positive

Table 3

PSHP controller gains and participation factors when VSWTs provide inertial frequency regulation (case 'A').

\begin{tabular}{|c|c|c|c|c|c|c|c|c|c|c|c|c|}
\hline \multirow{2}{*}{$\begin{array}{l}\mathrm{s}_{\mathrm{w}} \\
(\mathrm{m} / \mathrm{s})\end{array}$} & \multicolumn{2}{|c|}{ PSHP gains } & \multirow{2}{*}{$\begin{array}{l}\text { VSWT gains } \\
\mathrm{K}_{\mathrm{dn}}\end{array}$} & \multirow[t]{2}{*}{$\lambda_{\mathrm{i}}$} & \multirow[t]{2}{*}{$\zeta_{\mathrm{i}}$} & \multicolumn{6}{|c|}{ Participation factors } & \multirow[t]{2}{*}{ Oscillation mode } \\
\hline & $\delta$ & $\mathrm{T}_{\mathrm{r}}$ & & & & $\Delta q_{p}$ & $\Delta h$ & $\Delta z$ & $\Delta n$ & $\Delta \omega$ & $\Delta p_{\omega}$ & \\
\hline \multirow[t]{2}{*}{10} & 0.4 & 1.8 & 2.8 & $-0.106 \pm j 0.595$ & 0.175 & 0.253 & 0.368 & 0.217 & 0.162 & - & - & I \\
\hline & & & & $-0.087 \pm j 0.470$ & 0.182 & 0.102 & 0.239 & 0.353 & 0.296 & - & - & II \\
\hline \multirow[t]{2}{*}{20} & 0.4 & 1.4 & 3.2 & $-0.107 \pm \mathrm{j} 0.616$ & 0.171 & 0.257 & 0.349 & 0.216 & 0.178 & - & - & I \\
\hline & & & & $-0.066 \pm j 0.508$ & 0.129 & 0.121 & 0.245 & 0.334 & 0.290 & - & - & II \\
\hline
\end{tabular}



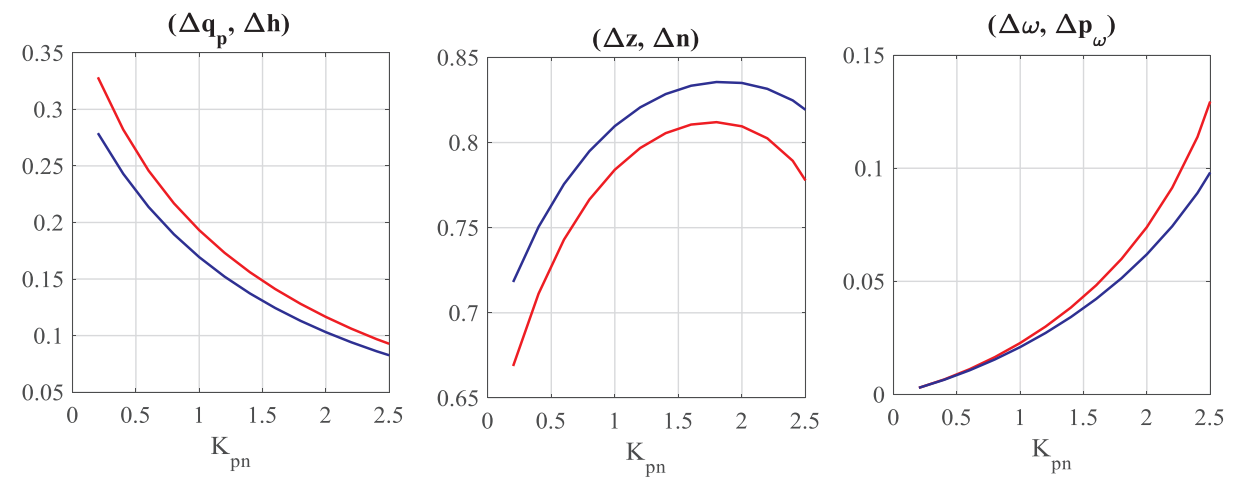

Fig. 9. Participation factors of dominant variables into electromechanical mode evolution due to VSWT proportional frequency regulation. Blue lines represent simulations assuming constant wind speed of $20 \mathrm{~m} / \mathrm{s}$ while red lines are for $10 \mathrm{~m} / \mathrm{s}$. (For interpretation of the references to colour in this figure caption, the reader is referred to the web version of this article.) real half plane) has been shaded grey. The electromechanical mode poles tend to the negative real values, whereas the water elasticity mode poles tend to the positive real values as the proportional gain is increased. In this case, the aeromechanical mode appears. With this VSWT regulation strategy, the poles of the two dominant oscillation modes, water elasticity and electromechanical mode, move to the real negative half plane, stabilizing the system. With these PSHP controller gains, the system would be unstable if the VSWTs did not provide frequency regulation because of having the electromechanical mode pole corresponding to $K_{p n}=0$ in the positive real half plane. Because the poles corresponding to the base case tuning have been displaced to the left in the water elasticity and electromechanical modes, it is expected that a better dynamic behaviour can be attained with the proportional control strategy than with the inertial strategy.

Table 4 lists the PSHP and VSWT controller gains, eigenvalues, damping ratios, and participation factors by applying the proposed criterion when the VSWTs provide proportional frequency regulation for wind speeds of $10 \mathrm{~m} / \mathrm{s}$ and $20 \mathrm{~m} / \mathrm{s}$.

The participation factors have been modified as when the VSWTs contribute to frequency regulation through the inertial control loop. The presence of the variables associated with the water elasticity mode in the electromechanical mode has decreased, preventing the hydraulic oscillations to be transmitted to the power system. It is also observed that the dominant variables of modes I and II do not influence the dynamics of the aeromechanical mode.

\subsection{Case 'C': inertial and proportional VSWT contribution to frequency regulation}

As with the cases described above, Fig. 12 shows the system's smallest damping ratio for case ' $\mathrm{C}$ '. The dashed lines correspond to $K_{p n}$ values and the dotted lines correspond to $K_{d r}$ which provide jointly the

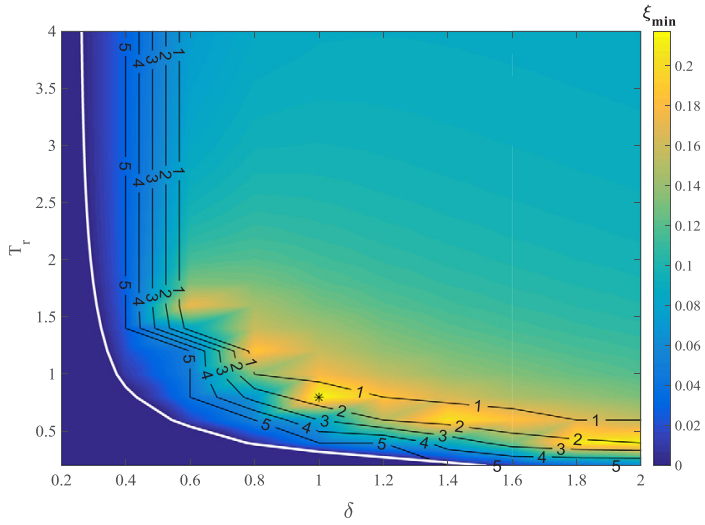

(a)

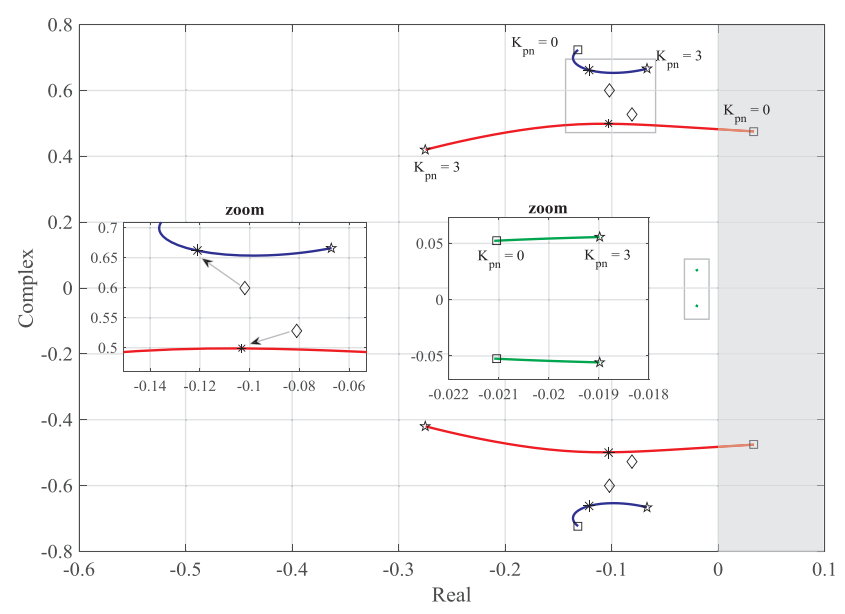

Fig. 11. Root locus plot when VSWTs contribute to frequency regulation with proportional control loop (sw $=20 \mathrm{~m} / \mathrm{s}$ ).

maximum damping ratio for each pair of values $\left(\delta, T_{r}\right)$. The unstable region is coloured in dark blue. Owing to the large number of controller gains involved in the system, the root locus technique is not effective.

Table 5 lists the PSHP and VSWT controller gains, eigenvalues, damping ratios, and participation factors by applying the proposed criterion when the VSWTs provide inertial and proportional frequency regulation for wind speeds of $10 \mathrm{~m} / \mathrm{s}$ and $20 \mathrm{~m} / \mathrm{s}$. Because of the proportional contribution, the values of the PSHP governor gains are significantly different from those obtained in the base case, as with case ' $\mathrm{B}$ '. The tendency observed in the previous cases is confirmed because the smallest damping ratio increases. Therefore, this control strategy is expected to be the most effective one to control the frequency.

The participation factors have been modified, preventing the

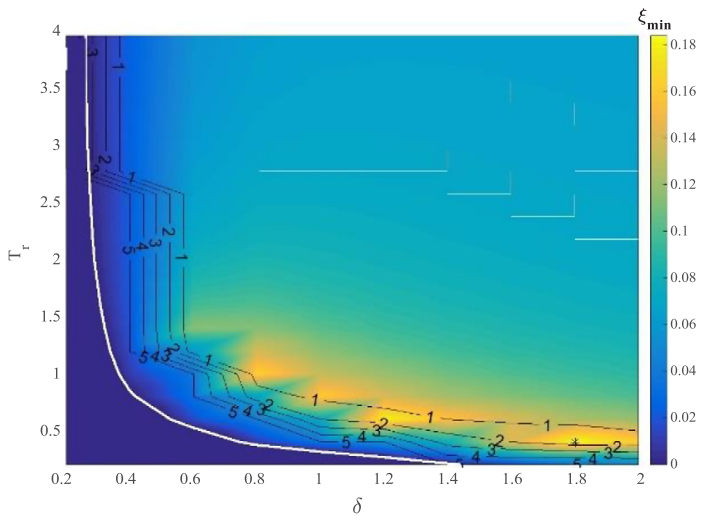

(b)

Fig. 10. Smallest damping ratio when VSWTs provide frequency regulation through a proportional control loop being $\mathrm{sw}=10 \mathrm{~m} / \mathrm{s}$ (a) and sw $=20 \mathrm{~m} / \mathrm{s}$ (b). 
Table 4

PSHP controller gains and participation factors when VSWTs provide proportional frequency regulation (case 'B').

\begin{tabular}{|c|c|c|c|c|c|c|c|c|c|c|c|c|}
\hline \multirow{2}{*}{$\begin{array}{l}\mathrm{s}_{\mathrm{w}} \\
(\mathrm{m} / \mathrm{s})\end{array}$} & \multicolumn{2}{|c|}{ PSHP gains } & \multirow{2}{*}{$\begin{array}{l}\text { VSWT gains } \\
\mathrm{K}_{\mathrm{pn}}\end{array}$} & \multirow[t]{2}{*}{$\lambda_{\mathrm{i}}$} & \multirow[t]{2}{*}{$\zeta_{\mathrm{i}}$} & \multicolumn{6}{|c|}{ Participation factors } & \multirow[t]{2}{*}{ Oscillation mode } \\
\hline & $\delta$ & $\mathrm{T}_{\mathrm{r}}$ & & & & $\Delta q_{p}$ & $\Delta h$ & $\Delta z$ & $\Delta n$ & $\Delta \omega$ & $\Delta p_{\omega}$ & \\
\hline 10 & 1.0 & 0.8 & 1.4 & $\begin{array}{l}-0.126 \pm j 0.604 \\
-0.132 \pm j 0.509 \\
-0.020 \pm j 0.054\end{array}$ & $\begin{array}{l}0.204 \\
0.251 \\
0.347\end{array}$ & $\begin{array}{l}0.252 \\
0.113 \\
0.000\end{array}$ & $\begin{array}{l}0.352 \\
0.237 \\
0.001\end{array}$ & $\begin{array}{l}0.219 \\
0.350 \\
0.033\end{array}$ & $\begin{array}{l}0.170 \\
0.286 \\
0.001\end{array}$ & $\begin{array}{l}0.001 \\
0.002 \\
0.476\end{array}$ & $\begin{array}{l}0.006 \\
0.012 \\
0.489\end{array}$ & $\begin{array}{l}\text { I } \\
\text { II } \\
\text { III }\end{array}$ \\
\hline 20 & 1.8 & 0.4 & 1.6 & $\begin{array}{l}-0.121 \pm j 0.662 \\
-0.103 \pm j 0.499 \\
-0.020 \pm j 0.053\end{array}$ & $\begin{array}{l}0.180 \\
0.202 \\
0.353\end{array}$ & $\begin{array}{l}0.307 \\
0.127 \\
0.000\end{array}$ & $\begin{array}{l}0.361 \\
0.230 \\
0.001\end{array}$ & $\begin{array}{l}0.174 \\
0.335 \\
0.034\end{array}$ & $\begin{array}{l}0.153 \\
0.291 \\
0.001\end{array}$ & $\begin{array}{l}0.001 \\
0.002 \\
0.476\end{array}$ & $\begin{array}{l}0.004 \\
0.015 \\
0.488\end{array}$ & $\begin{array}{l}\text { I } \\
\text { II } \\
\text { III }\end{array}$ \\
\hline
\end{tabular}

hydraulic oscillations to be transmitted to the power system owing to the decrease of the presence of variables associated with the water elasticity mode in the electromechanical mode. Because of the very high participation factors of the dominant variables of the aeromechanical mode into its own oscillation mode, it can be concluded that the dominant variables of modes I and II do not influence the dynamics of the aeromechanical mode.

As a summary of the modal analysis developed and the controllertuning criterion proposed, the evolution of the minimum damping ratio (orange lines) and the participation of the water elasticity mode dominant variables into the electromechanical mode (blue lines) are shown in Fig. 13. The reduction in participation of the water elasticity mode dominant variables is verified including the increase in the minimum damping ratio owing to the hybrid control strategies and the proposed tuning of PSHP and VSWT controllers.

The modal analysis developed, as well as the PSHP and VSWT controller tuning criterion proposed, are based on the simplified linear model. Therefore, both must be contrasted by simulations in a completely nonlinear model.

\section{Simulations and results}

To check the suitability of controller tuning, Jones et al. [66] suggested that it is enough to simulate a step, a ramp, and a random signal. In accordance to this methodology, three different events related to renewable source generation were simulated in [40]. Therefore, a load step, a wind speed ramp, and a real wind speed fluctuation [31], assumed as realistic events, have been simulated in the completely nonlinear model. To reinforce the results obtained from these simulations, a group of 100 synthetic wind speed fluctuations have been obtained

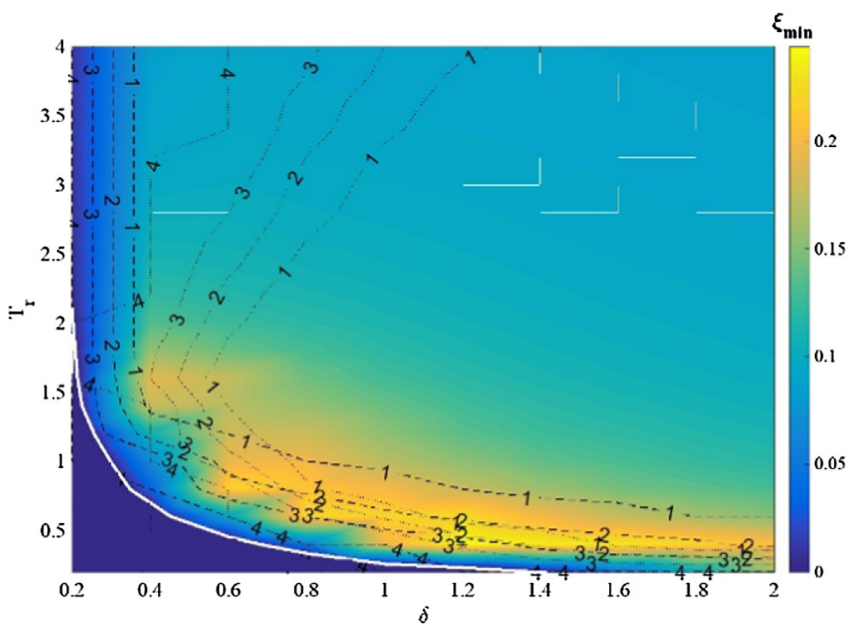

(a) from the real wind speed signal which have been also simulated. However, these results cannot be compared to the current experimental data, and it seems reasonable to expect a fairly good agreement because a similar model has been used in [47] for Dinorwig power plant, where the simulation results were sufficiently accurate compared to field measurements.

Cases 'A', 'B', and 'C' have been compared with the base case (frequency control provided only by PSHP) to highlight the variation of each parameter mentioned previously.

Figs. 14 and 15 show the dynamic response comparison between the base case and the different cases of VSWT contributions to frequency regulation ('A', 'B', and ' $C$ '), when a $5 \%$ power demand step is imposed, considering constant wind speeds of $10 \mathrm{~m} / \mathrm{s}$ and $20 \mathrm{~m} / \mathrm{s}$, respectively. A $12 \mathrm{~s}$ period oscillation is observed in the frequency response, corresponding to the oscillation period of the water hammer effect existing in the penstock. The proposed control strategies do not eliminate these oscillations, but dampen them, decreasing the oscillation amplitude and settling time. It can be verified that, regardless of the wind speed, the contribution of the VSWT to the frequency regulation is beneficial to the system, as it increases the value of the nadir. This confirms the observations made through the modal analysis. In addition, the VSWT contribution moderates the PSHP mechanical equipment movements.

When a wind speed ramp takes place and frequency regulation is only provided by the PSHP, as listed in Table 6, the frequency attains values outside the limits established by the TSO $(50 \mathrm{~Hz} \pm 0.15 \mathrm{~Hz})$ [65]. In addition, the mean frequency deviation (MFD) calculated based on Eq. (10), nadir, maximum frequency peak, and nozzle movement values are improved supposing a small increase in the movements of the VSWT blades.

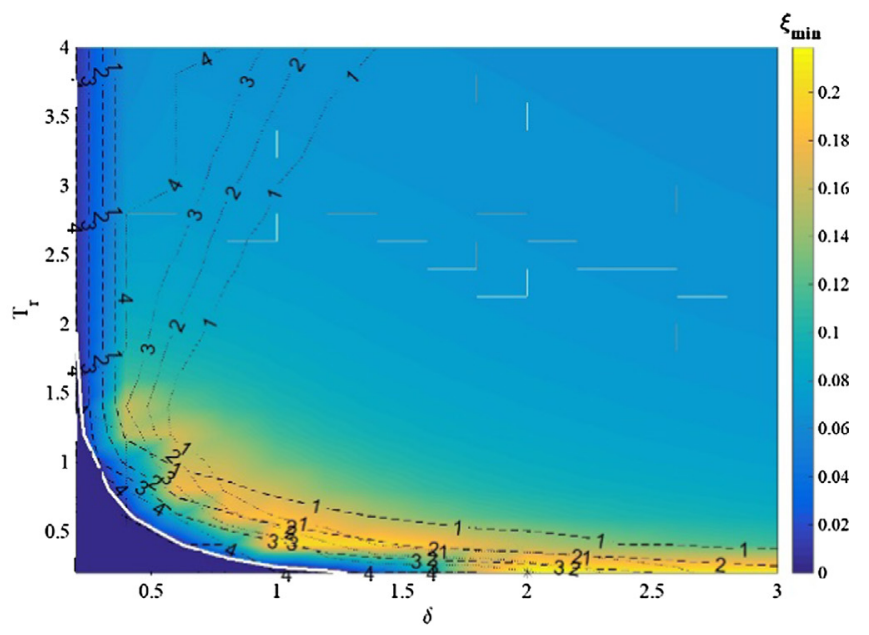

(b)

Fig. 12. Smallest damping ratio when VSWTs provide frequency regulation through inertial and proportional control loops being $\mathrm{sw}=10 \mathrm{~m} / \mathrm{s}$ (a) and $\mathrm{sw}=20 \mathrm{~m} / \mathrm{s}$ (b). 
Table 5

PSHP controller gains and participation factors when VSWTs provide inertial and proportional frequency regulation (case 'C').

\begin{tabular}{|c|c|c|c|c|c|c|c|c|c|c|c|c|c|}
\hline \multirow{2}{*}{$\begin{array}{l}\mathrm{S}_{\mathrm{w}} \\
(\mathrm{m} / \mathrm{s})\end{array}$} & \multicolumn{2}{|c|}{ PSHP gains } & \multicolumn{2}{|c|}{ VSWT gains } & \multirow[t]{2}{*}{$\lambda_{\mathrm{i}}$} & \multirow[t]{2}{*}{$\zeta_{\mathrm{i}}$} & \multicolumn{6}{|c|}{ Participation factors } & \multirow[t]{2}{*}{ Oscillation mode } \\
\hline & $\delta$ & $\mathrm{T}_{\mathrm{r}}$ & $\mathrm{K}_{\mathrm{dn}}$ & $\mathrm{K}_{\mathrm{pn}}$ & & & $\Delta q_{p}$ & $\Delta h$ & $\Delta z$ & $\Delta n$ & $\Delta \omega$ & $\Delta p_{\omega}$ & \\
\hline 10 & 1.2 & 0.4 & 2.8 & 3.4 & $\begin{array}{l}-0.155 \pm j 0.611 \\
-0.138 \pm j 0.525 \\
-0.020 \pm j 0.055\end{array}$ & $\begin{array}{l}0.246 \\
0.254 \\
0.342\end{array}$ & $\begin{array}{l}0.240 \\
0.133 \\
0.000\end{array}$ & $\begin{array}{l}0.323 \\
0.214 \\
0.002\end{array}$ & $\begin{array}{l}0.235 \\
0.351 \\
0.047\end{array}$ & $\begin{array}{l}0.192 \\
0.284 \\
0.001\end{array}$ & $\begin{array}{l}0.001 \\
0.002 \\
0.466\end{array}$ & $\begin{array}{l}0.009 \\
0.016 \\
0.484\end{array}$ & $\begin{array}{l}\text { I } \\
\text { II } \\
\text { III }\end{array}$ \\
\hline 20 & 2 & 0.2 & 3.2 & 3.8 & $\begin{array}{l}-0.143 \pm j 0.623 \\
-0.127 \pm j 0.561 \\
-0.020 \pm j 0.054\end{array}$ & $\begin{array}{l}0.224 \\
0.221 \\
0.347\end{array}$ & $\begin{array}{l}0.233 \\
0.136 \\
0.000\end{array}$ & $\begin{array}{l}0.303 \\
0.217 \\
0.001\end{array}$ & $\begin{array}{l}0.244 \\
0.351 \\
0.044\end{array}$ & $\begin{array}{l}0.209 \\
0.279 \\
0.002\end{array}$ & $\begin{array}{l}0.001 \\
0.002 \\
0.469\end{array}$ & $\begin{array}{l}0.010 \\
0.015 \\
0.484\end{array}$ & $\begin{array}{l}\text { I } \\
\text { II } \\
\text { III }\end{array}$ \\
\hline
\end{tabular}
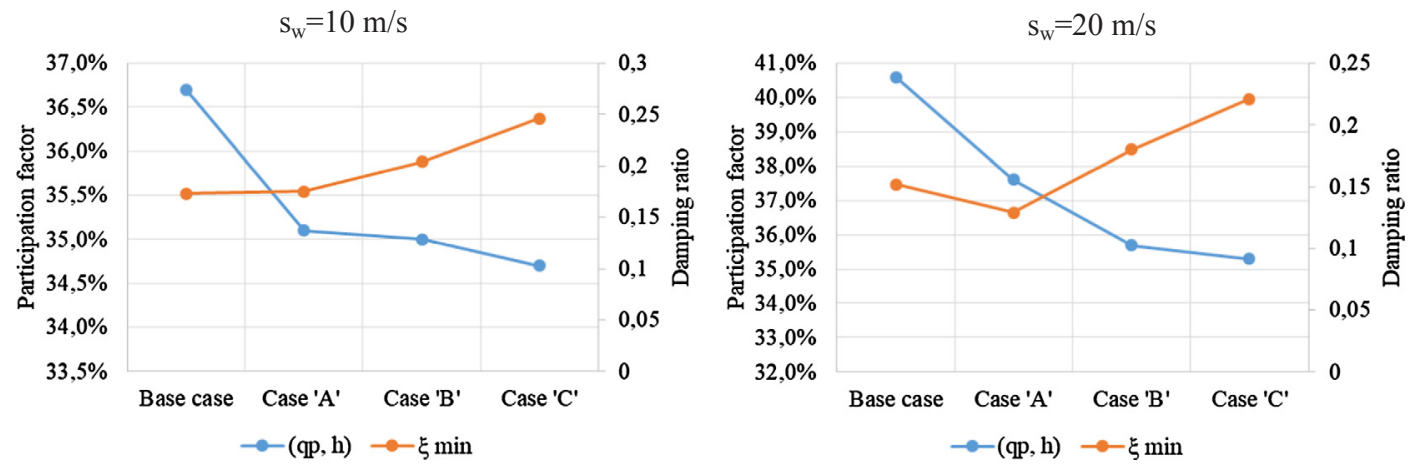

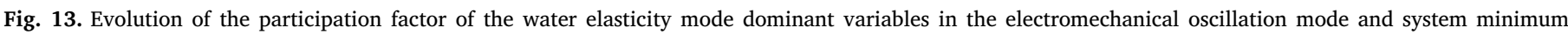
damping ratio.
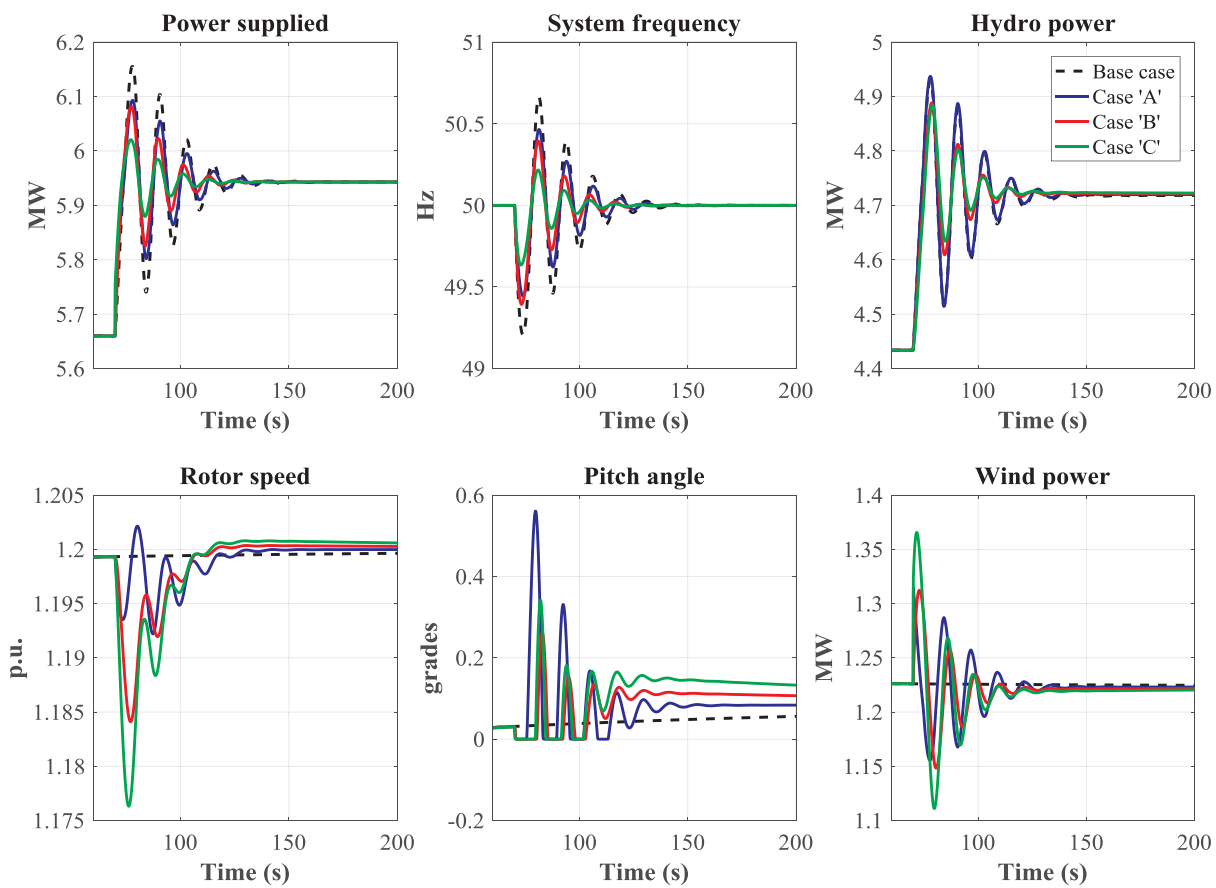

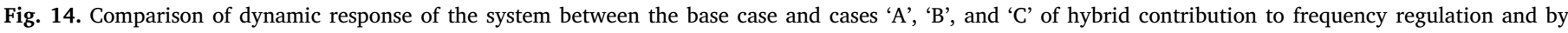
considering a sudden power demand variation and a constant wind speed of $10 \mathrm{~m} / \mathrm{s}$.

$M D F=\frac{\int_{0}^{t}\left|n-n_{r e f}\right|}{t}$

The frequency comparison from the simulation of wind speed fluctuations between the base case and VSWT contribution cases ' $\mathrm{A}$ ', ' $\mathrm{B}$ ', and ' $\mathrm{C}$ ' is shown in Fig. 16. It is observed that the frequency oscillations caused by wind speed fluctuations are clearly minimized, particularly when considering control strategies in which the inertial controls A and $\mathrm{C}$ are enabled. Moreover, the simulation results are summarized in
Table 7, listing for each strategy the wind energy generated, MFD, nadir, maximum frequency peak, nozzle movements per second, and blade angle movements per second.

In Table 8, the averages of the results obtained simulating the group of synthetic wind speed fluctuations are listed.

As observed in Tables 7 and 8, results obtained from the real wind speed fluctuation simulation and the averages of the results obtained by simulating the group of synthetic wind speed fluctuations match significantly. Furthermore, the MFD, nadir, maximum frequency peak, and 

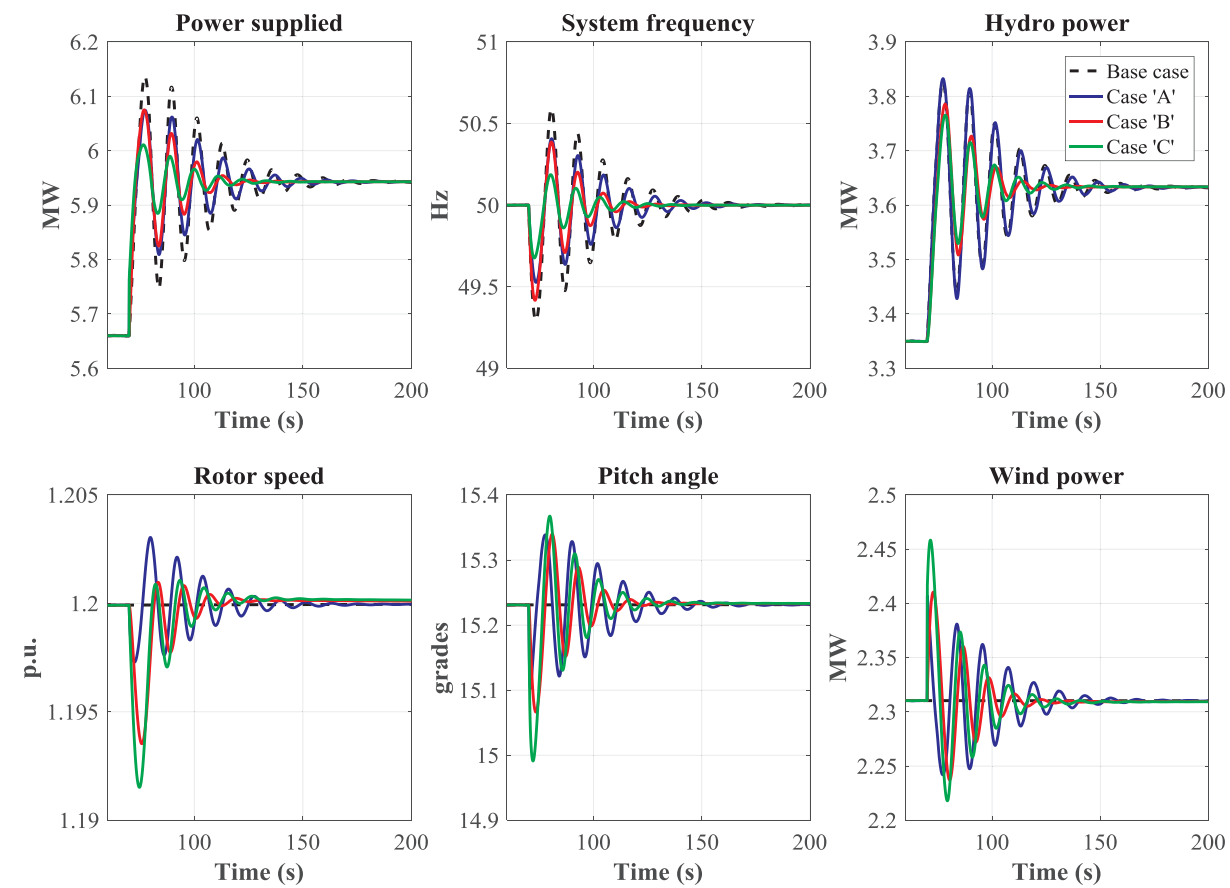

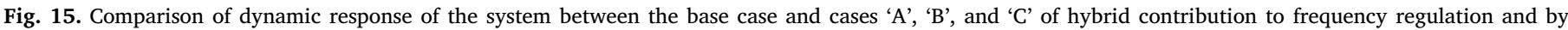
considering a sudden power demand variation and a constant wind speed of $20 \mathrm{~m} / \mathrm{s}$.

Table 6

Simulation results with a wind speed ramp.

\begin{tabular}{|c|c|c|c|c|c|c|c|c|c|c|}
\hline \multirow[t]{2}{*}{ Case } & \multicolumn{2}{|l|}{ MFD } & \multicolumn{2}{|l|}{ Nadir } & \multicolumn{2}{|c|}{ Max. Frequency peak } & \multicolumn{2}{|l|}{$\int|\Delta z| / t$} & \multicolumn{2}{|l|}{$\int|\Delta \beta| / t$} \\
\hline & $\mathrm{Hz}$ & $\Delta$ & $\mathrm{Hz}$ & $\Delta$ & $\mathrm{Hz}$ & $\Delta$ & $10^{-5}$ p.u. $/ \mathrm{s}$ & $\Delta$ & $\% / \mathrm{s}$ & $\Delta$ \\
\hline base & 0.0504 & & 49.8744 & & 50.3515 & & 14.029 & & 0.7268 & \\
\hline 'A' & 0.0056 & $-88.89 \%$ & 49.9996 & $0.25 \%$ & 50.0224 & $-0.65 \%$ & 2.0266 & $-85.55 \%$ & 0.7334 & $0.91 \%$ \\
\hline 'B' & 0.0188 & $-62.70 \%$ & 49.9798 & $0.21 \%$ & 50.1387 & $-0.42 \%$ & 5.2422 & $-62.63 \%$ & 0.7276 & $0.11 \%$ \\
\hline 'C' & 0.0072 & $-85.71 \%$ & 50.0000 & $0.25 \%$ & 50.0194 & $-0.66 \%$ & 3.6044 & $-74.31 \%$ & 0.7311 & $0.59 \%$ \\
\hline
\end{tabular}
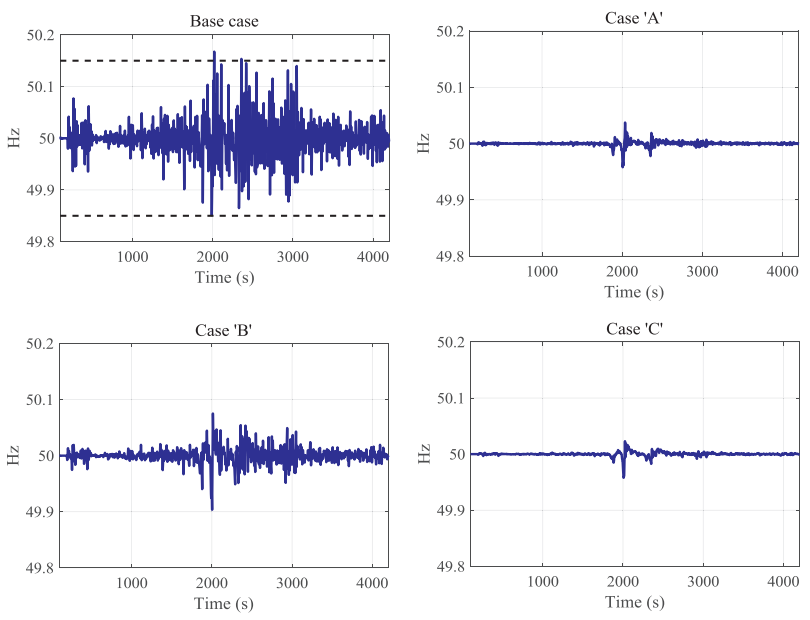

Fig. 16. System frequency comparison between base case and cases 'A', 'B', and ' $\mathrm{C}$ ' during wind speed fluctuations. Frequency limits required by the TSO are marked in dashed line.

nozzle movement values are improved in all cases owing to the VSWT contribution to frequency regulation, with a negligible loss of wind energy (less than $0.35 \%$ ). In both simulations, assuming variations in wind speed, it is verified that for the proposed cases, the VSWT contribution to frequency regulation results in a significant improvement in the MFD, nadir, and maximum peak of frequency. As to the mechanical parts, an important reduction in the movements of the turbine nozzle (more than $85 \%$ in cases ' $A$ ' and ' $C$ ') takes place, thereby increasing its remaining lifetime. These reductions in movements suppose an assumable increase (less than 10\%) in the movements of the VSWT blades. It can be observed that emulation of inertia improves the minimum frequency peaks as well as the MFD better than proportional control. Notwithstanding the above, the vast majority of these indicators reach an even better value when proportional control acts together with inertial control.

\section{Conclusions}

In this study, a modal analysis on the contribution to frequency regulation of a hybrid wind-hydro power plant was performed for the El Hierro isolated power system. The hybrid wind-hydro power plant committed in El Hierro was modelled in Matlab Simulink with enough detail to obtain comparable results with experimental models. From the mathematical model, certain realistic hypotheses have been assumed to simplify and linearize it, with the aim of undertaking the modal analysis. The oscillation modes that interfere with the dynamic behaviour of the system were identified from the state matrix by obtaining the eigenvalues and participation factors, identifying also the variables on which these modes depend. Three control strategies were analysed, comparing them with the cases in which the VSWTs do not provide frequency regulation.

As significant contributions of this study, it has been proved analytically from the position of the system poles that VSWT controller 
Table 7

Simulation results using a fluctuation of wind speed.

\begin{tabular}{|c|c|c|c|c|c|c|c|c|c|c|c|c|}
\hline Case & \multicolumn{2}{|c|}{ Wind energy } & \multicolumn{2}{|l|}{ MFD } & \multicolumn{2}{|l|}{ Nadir } & \multicolumn{2}{|c|}{ Maximum frequency peak } & \multicolumn{2}{|l|}{$\int|\Delta z| / t$} & \multicolumn{2}{|l|}{$\int|\Delta \beta| / t$} \\
\hline 'A' & 2.6617 & $-0.34 \%$ & 0.0018 & $-91.67 \%$ & 49.9581 & $0.21 \%$ & 50.0374 & $-0.26 \%$ & 9.9124 & $-87.98 \%$ & 0.0853 & $7.16 \%$ \\
\hline 'B' & 2.6704 & $-0.01 \%$ & 0.0083 & $-61.57 \%$ & 49.9036 & $0.11 \%$ & 50.0750 & $-0.18 \%$ & 23.187 & $-59.68 \%$ & 0.0845 & $6.16 \%$ \\
\hline 'C' & 2.6669 & $-0.14 \%$ & 0.0017 & $-92.13 \%$ & 49.9579 & $0.21 \%$ & 50.0229 & $-0.29 \%$ & 8.4037 & $-85.39 \%$ & 0.0873 & $9.67 \%$ \\
\hline
\end{tabular}

Table 8

Average results using 100 synthetic signals of wind speed.

\begin{tabular}{|c|c|c|c|c|c|c|c|c|c|c|c|c|}
\hline Case & \multicolumn{2}{|c|}{ Wind energy } & \multicolumn{2}{|l|}{ MFD } & \multicolumn{2}{|l|}{ Nadir } & \multicolumn{2}{|c|}{ Maximum frequency peak } & \multicolumn{2}{|l|}{$\int|\Delta z| / t$} & \multicolumn{2}{|l|}{$\int|\Delta \beta| / t$} \\
\hline base & 2.6914 & & 0.0284 & & 49.8217 & & 50.2087 & & 32.439 & & 0.0660 & \\
\hline 'B' & 2.6914 & $0.000 \%$ & 0.0061 & $-78.52 \%$ & 49.9562 & $0.27 \%$ & 50.0429 & $-0.33 \%$ & 11.195 & $-65.49 \%$ & 0.0681 & $3.182 \%$ \\
\hline 'C' & 2.6913 & $-0.004 \%$ & 0.0012 & $-95.78 \%$ & 49.9891 & $0.33 \%$ & 50.0077 & $-0.40 \%$ & 3.3132 & $-89.78 \%$ & 0.0688 & $4.242 \%$ \\
\hline
\end{tabular}

gains recommended for interconnected systems are not adequate for isolated systems. Also, a tuning criterion based on the smallest damping ratio has been proposed to unlink the hydraulic state variables from the electromechanical oscillation mode, preventing the hydraulic oscillations to be transmitted to the system frequency. Control strategies and tuning criterion extracted from this study have been evaluated by simulating different events related to fluctuations in wind speed or variations in power demand. As a general conclusion, it is worth noting the feasibility of operating the island power system without the diesel generators when there are sufficient wind potentials owing to the VSWT contribution to frequency regulation, supplying demand and maintaining the system frequency within the limits established by the TSO.

\section{Acknowledgements}

The work presented in this paper has been partially funded by the Spanish Ministry of Economy and Competitiveness under the project 'Value of pumped-hydro energy storage in isolated power systems with high wind power penetration' of the National Plan for Scientific and Technical Research and Innovation 2013-2016 (Ref. ENE2016-77951$\mathrm{R})$.

\section{References}

[1] Singh S, Singh M, Chandra Kaushik S. Feasibility study of an islanded microgrid in rural area consisting of PV, wind, biomass and battery energy storage system. Energy Convers Manage 2016;128:178-90.

[2] Caralis G, Zervos A. Analysis of the combined use of wind and pumped storage systems in autonomous Greek islands. IET Renew Power Gener 2007;1(1):49-60.

[3] Kaldellis J, Kavadias K, Christinakis E. Evaluation of the wind-hydro energy solution for remote islands. Energy Convers Manage 2001;42(9):1105-20.

[4] Vasconcelos H, Moreira C, Madureira A, Pecas Lopes J, Miranda V. Advanced Control Solutions for Operating Isolated Power Systems: Examining the Portuguese islands. IEEE Electrification Mag 2015;3(1):25-35.

[5] Bueno C, Carta J. Wind powered pumped hydro storage systems, a means of increasing the penetration of renewable energy in the Canary Islands. Renew Sustain Energy Rev 2006;10(4):312-40

[6] Ye B, Zhang K, Jiang J, Miao L, Li J. Towards a 90\% renewable energy future: a case study of an island in the South China Sea. Energy Convers Manage 2017:142:24-41.

[7] Albadi M, El-Saadany E. Overview of wind power intermittency impacts on power systems. Electr Power Syst Res 2010;80(6):627-32.

[8] Iglesias G, Carballo R. Wave resource in El Hierro- an island towards energy selfsufficiency. Renewable Energy 2011;36(2):689-98.

[9] Merino J, Veganzones C, Sánchez JA, Martinez S, Platero CA. Power system stability of a small sized isolated network supplied by a combined wind-pumped storage generation system: a case study in the Canary Islands. Energies 2012;5(7):2351-69.

[10] Ibrahim H, Ilinca A, Perron J. Energy storage systems-Characteristics and comparisons. Renew Sustain Energy Rev 2008;12(5):1221-50.

[11] Zhao H, Wu Q, Hu S, Xu H, Rasmussen CN. Review of energy storage system for wind power integration support. Appl Energy 2015;137:545-53.
[12] Kapsali M, Kaldellis J. Combining hydro and variable wind power generation by means of pumped-storage under economically viable terms. Appl Energy 2010;87(11):3475-85.

[13] Díaz-Gonzalez F, Sumper A, Gomis-Bellmunt O, Villafáfila-Robles R. A review of energy storage technologies for wind power applications. Renew Sustain Energy Rev 2012;16(4):2154-71.

[14] Pérez-Díaz JI, Jiménez J. Contribution of a pumped-storage hydropower plant to reduce the scheduling costs of an isolated power system with high wind power penetration. Energy 2016;109:92-104.

[15] Brown PD, Peças Lopes JA, Matos MA. Optimization of pumped storage capacity in an isolated power system with large renewable penetration. IEEE Trans Power Syst 2008;23(2):523-31.

[16] Makarov Y, Yang B, DeSteese J, Lu S, Miller C, Nyeng P, et al. Wide-area energy storage and management system to balance intermittent resources in the Bonneville Power Administration and California ISO control areas. Washington: Pacific Northwest National Laboratory Richland; 2008.

[17] Badihi H, Zhang Y, Hong H. Active power control design for supporting grid frequency regulation in wind farms. Annu Rev Control 2015;40:70-81.

[18] Gonzalez-Longatt F. Effects of the synthetic inertia from wind power on the total system inertia: simulation study. In: 2nd international symposium on environment friendly energies and applications. Newcastle upon Tyne, UK; 2012.

[19] Chamorro H, Ghandhari M, Eriksson R. Wind power impact on power system frequency response. Manhattan; 2013.

[20] Aziz A, Aman T, Stojcevski A. Frequency regulation capabilities in wind power plant. Sustainable Energy Technol Assess 2017.

[21] Lalor G, Mullane A, O'Malley M. Frequency control and wind turbine technologies. IEEE Trans Power Syst 2005;20(4):1905-13.

[22] Mullane A, O'Malley M. The inertial response of induction-machine-based wind turbines. IEEE Trans Power Syst 2005;20(3):1496-503.

[23] Morren J, de Haan S, Kling W. Wind turbines emulating inertia and supporting primary frequency control. IEEE Trans Power Syst 2006;21(1):433-4.

[24] Eriksson R, Modig N, Elkington K. Synthetic inertia versus fast frequency response: a definition. Vienna; 2016.

[25] Renuka T, Reji P. Frequency control of wind penetrated hydro-dominated power system. Kollam, India; 2015.

[26] Gonzalez-Longatt FM. Activation schemes of synthetic inertia controller for full converter wind turbine generators. Netherlands: Eindhoven; 2015.

[27] Gonzalez-Longatt F, Bonfiglio A, Procopio R, Bogdanov D. Practical limit of synthetic inertia in full converter wind turbine generators: simulation approach. Bulgaria: Bourgas; 2016.

[28] de Almeida R, Castronuovo E, Lopes J. Optimum generation control in wind parks when carrying out system operator requests. IEEE Trans Power Syst 2006;21(2):718-25.

[29] Courtecuisse V, Robyns B, Francois B, Petit M, Deuse J. Variable speed wind generators participation in primary frequency control. Wind Eng 2008;32(3):299-318.

[30] Mauricio JM, Marano A, Gómez-Expósito A, Martínez Ramos JL. Frequency regulation contribution through variable-speed wind energy conversion system. IEEE Trans Power Syst 2009;24(1):173-80.

[31] Martínez-Lucas G, Sarasúa JI, Sánchez-Fernández JÁ. Frequency regulation of a hybrid wind-hydro power plant in an isolated power system. Energies 2018;11(1):1-25.

[32] Pezic M, Cedrés VM. Unit commitment in fully renewable, hydro-wind energy systems. Sweden: Stockholm; 2013

[33] Hušek P. PID controller design for hydraulic turbine based on sensitivity margin specifications. Int J Electr Power Energy Syst 2014;55:460-6.

[34] Sarasúa J, Elías P, Martínez-Lucas G, Pérez-Diaz J, Wilhelmi J, Sánchez J. Stability analysis of a run-of-river diversion hydropower plant with surge tank and spillway 
in the head pond. The Scientific World J 2014;2014:1-13.

[35] Strah B, Kuljaca O, Vukic Z. Speed and active power control of hydro turbine unit. IEEE Trans Energy Convers 2005;20(2):424-34.

[36] Fernández R, Mantz R, Battaiotto P. Impact of wind farms on a power system. An eigenvalue analysis approach. Renewable Energy 2007;32:1676-88.

[37] Amjady N, Reza Ansari M. Small disturbance voltage stability assessment of power systems by modal analysis and dynamic simulation. Energy Convers Manage 2008;49:2629-41.

[38] Sarasúa JI, Pérez-Díaz JI, Wilhelmi JR, Sánchez-Fernández JÁ. Dynamic response and governor tuning of a long penstock pumped-storage hydropower plant equipped with a pump-turbine and a doubly fed induction generator. Energy Convers Manage 2015;106:151-64.

[39] Martínez-Lucas G, Sarasúa JI, Sánchez JÁ, Wilhemi JR. Power-frequency control of hydropower plants with long penstocks in isolated systems with wind generation. Renewable Energy 2015;83:245-55.

[40] Martinez-Lucas G, Sarasúa JI, Sánchez-Fernández JÁ, Wilhelmi JR. Frequency control support of a wind-solar isolated system by a hydropower plant with long tail-race tunnel. Renewable Energy 2016;90:362-76.

[41] Silva PC, Nicolet C, Grillot P, Drommi J-L, Kawkabani B. Assessment of power swings in hydropower plants through high-order modeling and eigenanalysis. IEEE Trans Ind Appl 2017;53(4):3345-54.

[42] ENERCON GmbH. "ENERCON product overview". Enercon GmbH, Aurich, Germany; 2016.

[43] Canary Government. Anuario Energético de Canarias 2015. Consejería de Economía, Industria, Comercio y Conocimiento; 2016.

[44] Red Electrica de España. El Sistema Electrico Español en 2016. Madrid: Red Electrica de España; 2017.

[45] Platero C, Nicolet C, Sánchez J, Kawkabani B. Increasing wind power penetration in autonomous power systems through no-flow operation of Pelton turbines. Renewable Energy 2014;68:515-23.

[46] Carrillo C, Obando Montaño A, Cidrás J, Díaz-Dorado E. Review of power curve modelling for wind turbines. Renew Sustain Energy Rev 2013;21:572-81.

[47] Mansoor S, Jones D, Bradley F, Jones G. Reproducing oscillatory behaviour of a hydroelectric power station by computer simulation. Control Eng Pract 2000;8(11):1261-72.

[48] Chaudhry M. Applied hydraulic transients. 2d ed. New York: Van Nostrand; 1987.

[49] Nicolet C, Greiveldinger B, Hérou JJ, Kawkabani B, Allenbach P, Simond J-J, et al High-order modeling of hydraulic power plant in islanded power network. IEEE Trans Power Syst 2007;22(4):1870-80.

[50] IEEE Working Group. Hydraulic turbine and turbine control models for system dynamic studies. IEEE Trans Power Syst 1992;7(1):167-79.
[51] Miller NW, Price WW, Sanchez-Gasca JJ. Dynamic modeling of GE 1.5 and 3.6 wind turbine-generators. GE Power Syst 2003.

[52] Bhatt P, Roy R, Ghoshal S. Dynamic participation of doubly fed induction generator in automatic generation control. Renewable Energy 2011;36:1203-13.

[53] Sun Y-Z, Zhang Z-S, Li G, Lin J. Review on frequency control of power systems with wind power penetration. In: International conference on power system technology (POWERCON), Hangzhou, China; 2010.

[54] Ahmadyar AS, Verbic G. Control strategy for optimal participation of wind farms in primary frequency control. Netherlands: Eindhoven; 2015.

[55] Duong MQ, Grimaccia F, Leva S, Mussetta M, Ogliari E. Pitch angle control using hybrid controller for all operating regions of SCIG wind turbine system. Renewable Energy 2014;70:197-203.

[56] Yin X-X, Lin Y-G, Li W, Gu Y-J, Wang X-J, Lei P-F. Design, modeling and implementation of a novel pitch angle control system for wind turbine. Renewable Energy 2015;81:599-608.

[57] Yin X-X, Lin Y-G, Li W, Gu Y-J. Integrated pitch control for wind turbine based on a novel pitch control system. J Renew Sustain Energy 2014;6.

[58] Honrubia-Escribano A, Gómez-Lázaro E, Fortmann J, Sørensen P, Martin-Martinez S. Generic dynamic wind turbine models for power system stability analysis: a comprehensive review. Renew Sustain Energy Rev 2018;81(2):1939-52.

[59] Nanou S, Tsourakis G, Vournas CD. Full-converter wind generator modelling for transient stability studies. Norway: Trondheim; 2011.

[60] Shang L, Hu J, Yuan X, Chi Y. Understanding Inertial Response of Variable-Speed Wind Turbines by Defined Internal Potential Vector. Energies 2016;22(10).

[61] Yin X-X, Lin Y-G, Li W, Gu Y-J, Lei P-F, Liu H-W. Sliding mode voltage control strategy for capturing maximum wind energy based on fuzzy logic control. Electr Power Energy Syst 2015;70:45-51.

[62] Papangelis LN, Vournas CD. Design principles of wind turbine inertia emulators for autonomous systems. In: Proceedings of the 19th world congress the international federation of automatic control, Cape Town, South Africa; 2014.

[63] Liu X, Liu C. Eigenanalysis of oscillatory instability of a hydropower plant including water conduit dynamics. IEEE Trans Power Syst 2007;22(2):675-81.

[64] Yang W, Norrlund P, Chung CY, Yang J, Lundin U. Eigen-analysis of hydraulicmechanical-electrical coupling mechanism for small signal stability of hydropower plant. Renewable Energy 2018;115:1014-25.

[65] Red Electrica de España. P.O. 1: Funcionamiento de los sistemas eléctricos insulares y extrapeninsulares. Boletín Oficial del Estado 10-8-2012, 2012;57263-495.

[66] Jones D, Mansoor S, Aris F, Jones G, Bradley D, King D. A standard method for specifying the response of a hydroelectric plant in frequency-control mode. Electr Power Syst Res 2004;68:19-32. 